\title{
ADVANCED MATERIALS: INFORMATION AND ANALYSIS NEEDS
}

\author{
T. Randall Curlee \\ Sujit Das \\ Russell Lee \\ David Trumble \\ Energy Division \\ Oak Ridge National Laboratory \\ Oak Ridge, Tennessee 37831-6205
}

Date Published: September 1990

Prepared by the

OAK RIDGE NATIONAL LABORATORY

OAK RIDGE, TN 37831-6205

Operated by

MARTIN MARIETTA ENERGY SYSTEMS, INC.

for the

U.S. DEPARTMENT OF ENERGY

under Contract No. DE-AC05-84OR21400

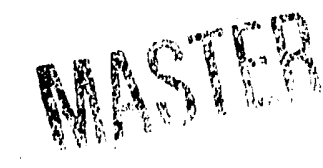




\section{ACKNOWLEDGEMENTS}

Charles Sorrell and Robert Brown of U.S. Bureau of Mines provided many insights and provided helpful critiques and comments. Professor William Lyons, a political scientist with the University of Tennessee assisted in the design and implementation of the questionnaire. Comments by several scientists from ORNL's Metals and Ceramics Division on the questionnaire were very helpful.

Juanita Hunt and Cathy Gaudreau did a masterful job on word processing the manuscript. Their contributions are gratefully acknowledged. Elias Whitfield and Gail Anderson did an excellent job on editing the manuscript. 
TABLE OF CONTENTS

ABSTRACT $\ldots \ldots \ldots \ldots \ldots \ldots \ldots \ldots \ldots \ldots \ldots \ldots \ldots \ldots \ldots \ldots \ldots \ldots \ldots \ldots$

1. INTRODUCTION $\ldots \ldots \ldots \ldots \ldots \ldots \ldots \ldots \ldots \ldots \ldots \ldots \ldots \ldots \ldots \ldots$

2. A REVIEW OF INFORMATION CURRENTLY PROVIDED BY BOM ON

TRADITIONAL MATERIALS $\ldots \ldots \ldots \ldots \ldots \ldots \ldots \ldots \ldots \ldots \ldots \ldots$

3. THE DEFINITION AND CLASSIFICATION OF ADVANCED MATERIALS . . . , 7

4. FUNDAMENTAL DIFFERENCES BETWEEN ADVANCED AND

TRADITIONAL MATERIALS AND IMPLICATIONS FOR INFORMATION

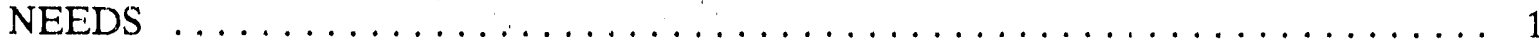

4.1 ADVANCED MATERIALS DISPLAY DIFFERENT PHYSICAL AND

CHEMICAL PROPERTIES -- SOME OF WHICH ARE SUPERIOR AND

SOME OF WHICH ARE INFERIOR TO TRADITIONAL MATERIALS. . . . . 16

4.2. THE RELATIVE IMPORTANCE OF INPUTS (I.E., HUMAN CAPITAL,

PHYSICAL CAPITAL, LABOR, ENERGY, AND MATERIALS) IN THE

RESEARCH, DEVELOPMENT, AND PRODUCTION OF ADVANCED

MATERIALS MAY BE SIGNIFICANTLY DIFFERENT. . . . . . . . . . . . . 17

4.3. THE RESEARCH, DEVELOPMENT, AND PRODUCTION OF

ADVANCED MATERIALS REQUIRE A BROADER RANGE OF

EXPERTISE AND SCIENTIFIC KNOWLEDGE THAN DO

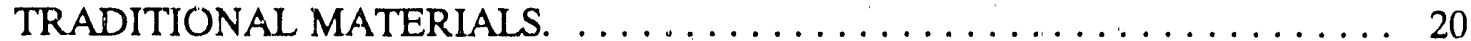

4.4 ADVANCED MATERIALS EXHIBIT GREATER POTENTIAL, FOR

RAPID TECHNOLOGICAL ADVANCE AND MARKET PENETRATION

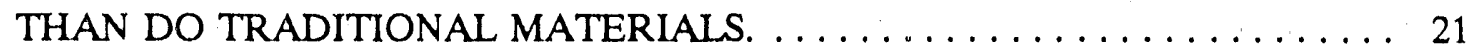

4.5 PROPERTIES OF ADVANCED MATERIALS CAN BE CUSTOMIZED . . . . 23

4.6 THE FABRICATION OF ADVANCED MATERIALS IS GENERALLY

MORE DIFFICULT THAN IS THE CASE WITH TRADITICINAL

MATERIALS.

4.7 SOME EVIDENCE SUGGESTS THAT THE ECONOMIES OF SCALE:

IN THE PP.ODUCTION OF ADVANCED MATERIALS MAY BE LESS

THAN IN THE PRODUCTION OF 'TRADITIONAL MATERIALS. . . . . . . 25

4.8 THE PRODUCTION OF BY-PRODUCTS IS LESS COMMON WITH

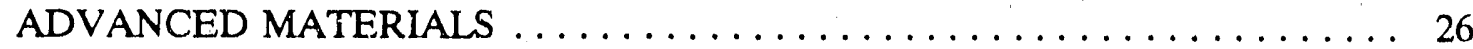

4.9 THE POTENTIAL FOR RECYCLING ADVANCED MATERIALS IS

MORE LIMITED THAN IS THE CASE WITH MOST TRADITIONAL

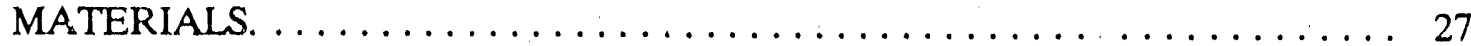

4.10 THE ENVIRONMENTAL CONSEQIENCES OF THE PRODUCTION, USE, AND/OR DISPOSAL OF ADVANCED MATERIALS MAY DIFFER SIGNIFICANTLY FROM THOSE OF TRADITIONAL MATERIALS. . . . . . . 
4.11 THE LIFE-CYCLE COSTS AND BENEFITS OF ADVANCED MATERIALS DIFFER SIGNIFICANTLY FROM THOSE OF

TRADITIONAL MATERIALS. ......................... 29

4.12 HISTORICAL DATA ON ALL ASPECTS OF ADVANCED

MATERIALS IS QUITE LIMITED $\ldots \ldots \ldots \ldots \ldots \ldots \ldots \ldots \ldots \ldots \ldots \ldots, 31$

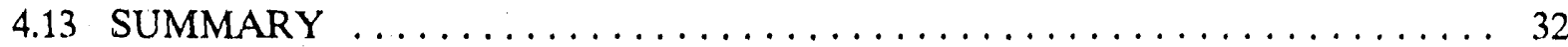

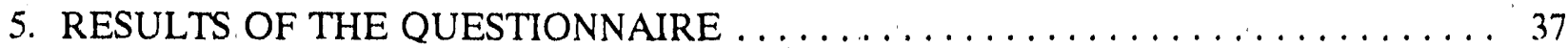

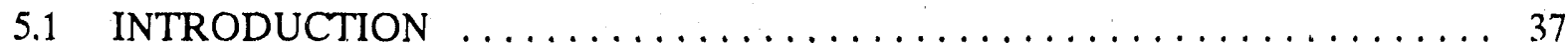

5.2 QUESTIONNAIRE DEVELOPMENT $\ldots \ldots \ldots \ldots \ldots \ldots \ldots \ldots \ldots \ldots, 37$

5.3 DESCRIPTION OF SAMPLE POPULATION $\ldots \ldots \ldots \ldots \ldots \ldots \ldots \ldots, 38$

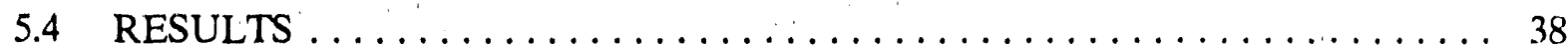

5.4.1 Response Rate of the Sample ...................... 38

5.4 .2 Definition of Advanced Materials ...................... 39

5.4 .3 Advanced Materials Categories $\ldots \ldots \ldots \ldots \ldots \ldots \ldots \ldots \ldots \ldots, 42$

5.4.4 Differences Between Traditional and Advanced Materials ........... 47

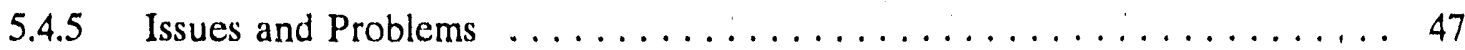

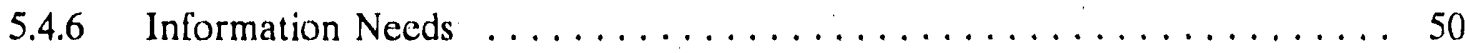

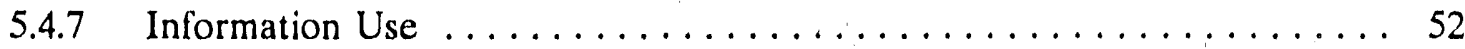

6. RESULTS OF THE QUESTIONNAIRE AND CONCEPTUAL ASSESSMENT:

COMPARISONS AND RESOLUTIONS OF DIFFERENCES $\ldots \ldots \ldots \ldots \ldots \ldots .55$

6.1. POINTS LEADING FROM THE DISCUSSION OF DEFINITIONS AND

CLASSIFICATION SCHEMES ...................... 55

6.2. POINTS LEADING FROM FUNDAMENTAL DIFFERENCES BETWEEN

ADVANCED AND TRADITIONAL MATERIAIS $\ldots \ldots \ldots \ldots \ldots \ldots \ldots .56$

6.2.1 Advanced and Traditional Materials Differ in Terms of Physical and

Chemical Properties .......................... 56

6.2.2 Advanced and Traditional Materials Differ in Terms of the Importance of

Capital, Labor, Material, and Energy Inputs $\ldots \ldots \ldots \ldots \ldots \ldots \ldots . . \ldots 7$

6.2.3 The R\&D and Production of Advanced Materials Require a Brcader

Range of Expertise and Scientific Knowledge than do Traditional Materials 58

6.2.4 As Compared to Traditional Materials, Advanced Materials Have the

Potential for More Rapid Technological Advance and Market Penetration

6.2.5 Advanced Materials Can Be Customized More for Specific Applications Than

Can Traditional Materials .......................... 59

6.2.6 The Fabrication of Advanced Materials Is Generally More Difficult than Is the Case with Traditional Materials ................... 60

6.2.7 Raw Materials for Advanced Materials May Be Crucially Linked to the Production of By-Products from Traditional Materials Manufacture ..... 60

6.2.8 Advanced Materials May Significantly Affect Markets for Traditional Materials .............................. 61

6.2.9 Advanced Materials Are More Difficult to Recycle than Are Traditional Materials

6.2.10 The Environmental Consequences of Producing, Using, and Disposing of Advanced Materiais May Differ Significantly from Traditional Materials .. 62

6.2.11 Advanced Materials Exhibit Different Life-Cycle Cost than do

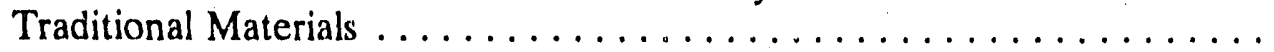


6.2.12 The Structure of the Market for Advanced Materials Differs from that for Traditional Materials . . . . . . . . . . . . . . . . . 63

6.2.13 The U.S. May Be at a Disadvantage in Competing with Foreign Competitors in the Advanced Materials Market ............. 63

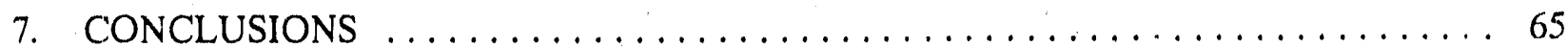

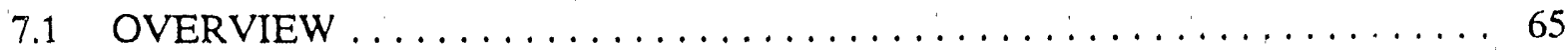

7.2 MATERIALS OF GREATEST INTEREST $\ldots \ldots \ldots \ldots \ldots \ldots \ldots \ldots$

7.3 THE TYPES OF INFORMATION THAT SHOULD BE EMPHASIZED . . . . 67

7.4 ANALYSIS AND OTHER ISSUES $\ldots \ldots \ldots \ldots \ldots \ldots \ldots \ldots \ldots \ldots \ldots \ldots$

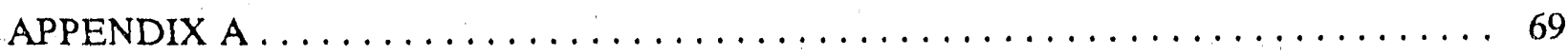

BIBLIOGRAPHY $\ldots \ldots \ldots \ldots \ldots \ldots \ldots \ldots \ldots \ldots \ldots \ldots \ldots \ldots \ldots \ldots \ldots$ 


\section{LIST OF FIGURES}

Figure 5.1 Respondents' opinions about the components important to the definition of advanced materials

\section{LIST OF TABLES}

Table 2.1 Minerals and materials routinely included in Minerals Yearbook $\ldots \ldots \ldots \ldots$

Table 2.2 Typical table of contents for Minerals Yearbook $\ldots \ldots \ldots \ldots \ldots \ldots \ldots \ldots$

Table 2.3 Basic outline of commodity chapters in Mineral Facts and Problems $\ldots \ldots \ldots 6$

Table 4.1 Summary of fundamental differences between advanced and traditional materials and information needs and analysis $\ldots \ldots \ldots \ldots \ldots \ldots \ldots \ldots \ldots \ldots \ldots$

Table 5.1 Employment breakdown of respondents $\ldots \ldots \ldots \ldots \ldots \ldots \ldots \ldots$

Table 5.2 Most important advanced materials category to respondents $\ldots \ldots \ldots \ldots \ldots$

Table 5.3 Descending order of interest to the respondents for various subcategories within 11 major groups of advanced materials $\ldots \ldots \ldots \ldots \ldots \ldots \ldots \ldots$

Table 5.4 Degree of importance attributed by respondents to various advanced materials . . . 45

Table 5.5 Differences between traditional and advanced materials $\ldots \ldots \ldots \ldots \ldots$

Table 5.6 Opinions about important issues and problems faced by the increased use of advanced materials . . . . . . . . . . . . . . . . 49

Table 5.7 Interest in obtaining the types of information for various categories of

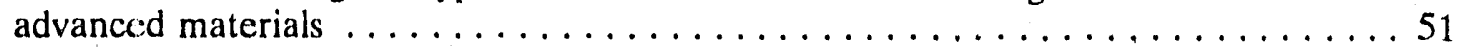

Table 5.8 The use of information for various categories of advanced materials $\ldots \ldots \ldots \ldots 53$

$$
\mathrm{ix} / \mathrm{x}
$$




\section{ABSTRACT}

This report presents the findings of a study to identify the types of information and analysis that are needed for advanced materials. The project was sponsored by the U.S. Bureau of Mines $(B O M)$. It includes a conceptual description of information needs for advanced materials and the development and implementation of a questionnaire on the same subject.

The study reviews the information that has been provided historically by BOM on traditional materials. The discussion notes the difficulties that exist in defining and classifying advanced materials. These difficulties complicate any assessment of advanced materials in the aggregate.

This report identifies twelve fundamental differences between advanced and traditional materials and discusses the implications of these differences for data and analysis needs. Advanced and traditisnal materials differ signilicantly in terms of physical and chemical properties. Advanced material properties can be customized more easily. The production of advanced materials may dilfer from traditional materials in terms of inputs, the importance of by-products, the importance of different processing steps (especially fabrication), and scale economies. The potential for change in advanced matc rials characteristics and markets is greater and is derived from the marriage of radically different matcrials and processes. The cost/benefit structure over the life of an advanced material may differ significantly from that of a traditional material, suggesting that traditional economic assessments may not be applicable to advanced materials.

These fundamental differences indicate a need for "road maps" to direct interested individuals to sources of technical and market data. There is also a need to establish meaningful boundaries for advanced materials in terms of input materials and products (i.e., when in the processing chain does a material become advanced, and when does an advanced material become a product?). In many cases the categories of information needed with respect to advanced materials are the same as with traditional materials. However, the primary focus of those general categories may differ sharply (e.g., materials vulnerability).

As more data an! other information are collected, BOM can assist domestic industries and policy makers by analyzing important issues. These issues include (1) forecasting the potential substitution and market penetration of advanced materials; (2) assessing the impacts of different organizational structures on research, development, and production of advanced materials; (3) estimating life-cycle costs and benefits of advanced materials and the discount rates used by adopters of these new materials; and (4) examining the potential for recycling advanced materials and the potential environmental consequences of producing and using advanced materials. Identifying information needs and analyses for advanced materials requires a fundamental rethinking of why information of various typer is important and to whom and for what purposes that information may be useful.

In addition to the conceptual study, a questionnaire was developed and implemented to assess the opinions of people who are likely users of BOM information on advanced materials. The results of the questicnnaire, which was sent to about 1000 people, generally confirm the propositions set forth in the conceptual part of the study. The results also provide data on the categories of advanced materials and the types of information that are of greatest interest to potential users. 


\section{INTRODUCTION}

The Energy Division of the Oak Ridge National Laboratory is currently assessing the information needs for an advanced materials database for the U.S. Bureau of Mines (BOM). This report presents the findings of the first phase of that work. In broad terms, the first phase includes a conceptual description for a new information database on advanced materials and recommendations for the use of these data.

BOM has traditionally provided data on and analyses of individual metals and minerals in publications such as the Minerals Yearbook, Mineral Facts and Problems, and Mineral Perspectives. Data and analyses are given or pertinent legislation and government programs, production, consumption, imports, exports, producer prices, consumer stocks, and technology. The development of a comparable, periodically updated information database for advanced materials requires a new assessment of the types of information that should be gathered and provided by BOM. Ideally, this information should be relatively concise and capable of being updated periodically, and it should represent the areas of interest and concern to industry and policy makers.

In developing a conceptual design for a new advanced materials information database, it is necessary to uncover the fundamental differences between advanced materials and traditional materials and to assess the implications of those differences for information needs. It is also important to assess how information on advancid materials might be used to study the major issues facing the development and use of advanced materials. This report addresses both concerns.

Findings are presented in six sections. Section 2 reviews the information on traditional materials BOM currently provides. Section 3 examines the problem of defining and classifying advanced materials and discusses the implications of the inability to define advanced materials precisely. Section 4 delves into the fundamental differences that may distinguish advanced materials from traditional materials. For each fundamental difference identified, the difference is discussed in 
conceptual terrns, an example of the difference is cited, and the implications of the difference in information needs are laid out. Where appropriate, special studies are suggested to address the major issues in the development and use of advanced materials. Note that the types of information currently being provided hy $\mathrm{BOM}$ on traditional materials are, in many instances, of basic importance to industry and policy-makers -- regardless of whether the material is traditional or advanced. The discussion in Section 4 focuses on key differences between traditional and advanced materials and the implications of those differences in modifying the current format and types of information provided. Section 5 reports the findings of a questionnaire to assess what experts believe are the most urgent and important information needs for advanced materials. jection 6 compares the suggestions for information needs derived from the conceptual discussion in Section 4 with the findings of the questionnaire. Attempts are made to resolve the discrepancies between the conceptual section and the findings of the questionnaire. The final section summarizes the conclusions of this phase of the study. 


\section{A REVIEW OF INFORIMATION CIJRRENTLY PROVIDED BY BOM ON TRADITIONAL MATERIALS}

BOM has historically provided information on numerous minerals and materials and has published statistical data and analyses in several periodic reports. Those reports include the Minerals Yearbook, Mineral Industry Survey, Mineral Commodity Summaries, Mineral Facts and Problems (now combined with Minerals Yearbook), Mineral Perspectives, and Minerals Today.

Minerals Yearbook provides a wide rangs of technical and market information about more than 70 minerals and materials. Information about both domestic and international markets is included. Table 2.1 lists the minerals and materials routinely included in Minerals Yearbook. Table 2.2 presents a representative table of contents for each of the minerals and materials included in the publication.

Mineral Industry Surveys provides monthly, quarterly, or annual reports that contain statistical and/or economic data on non-fuel mineral commodities. The publication provides timely information to industry and government agencies on production, distribution, inventories, and consumption of traditional minerals and materials.

Mineral Commodity Summaries provides concise information on mineral production, resources, reserves, imports, exports, uses, recycling, substitution possibilities, environmental considerations, tariffs, relevant government programs, and other miscellaneous information. The publication covers some 90 minerals and materials and is published in January of each year.

Mineral Facts and Problems, published every five years, furnished supply and demand forecasts for various minerals and materials in addition to summar; information also presented in Minerals Yearbook, Mineral Commodity Summaries, and Mineral Industry Surveys. Mineral Facts and Problems provided more detail than the other more frequent publications and covered such 
Table 2.1 Minerals and materials routinely included in Minerals Yearbook

\begin{tabular}{|c|c|c|}
\hline Abrasive materials & Gem stones & Perlite \\
\hline Aluminum & Gold & Phosphate rock \\
\hline Antimony & Graphite & Platinum-group metals \\
\hline Asbestos & Gypsum & Potash \\
\hline Barite & Helium & Pumice and pumicite \\
\hline Bauxite and alumina & Iodine & $\begin{array}{l}\text { Rare-earth minerals and } \\
\text { metals }\end{array}$ \\
\hline Beryllium & Iron and steel & Salt \\
\hline Bismuth & Iron and steel scrap & Sand and gravel \\
\hline Boron & Iron ore & Silicon \\
\hline Bromine & Iron oxide pigulents & Silver \\
\hline Cadmium & $\begin{array}{l}\text { Kyanite and related } \\
\text { materials }\end{array}$ & Slag -- Iron and steel \\
\hline $\begin{array}{l}\text { Calcium and calcium } \\
\text { compounds }\end{array}$ & Lead & Sodium compounds \\
\hline Cement & Lime & Stone, crushed \\
\hline Chromium & Lithium & Stone, dimension \\
\hline Clays & Magnanese & Sulfur \\
\hline Cobalt & Magnesium & Thorium \\
\hline Columbium and tantalum & Magnesium compounds & Tin \\
\hline Copper & Mercury & Titanium \\
\hline Diatomite & Mica & Tungsten \\
\hline $\begin{array}{l}\text { Feldspar, nepheline syenite, } \\
\text { and aplite }\end{array}$ & Molybdenum & Vanadium \\
\hline Ferroalloys & Nickel & Vermiculite \\
\hline Fluorspar & Nitrogen & Zinc \\
\hline Gallium & Peat & Zirconium and hafnium \\
\hline
\end{tabular}




\begin{tabular}{|c|c|}
\hline \multicolumn{2}{|c|}{ Table 2.2 Typical table of contents for Minerals Yearbook } \\
\hline I. & Legislation and Government Programs \\
\hline II. & Domestic Production \\
\hline III. & Consumption \\
\hline IV. & Stocks \\
\hline $\mathrm{V}$. & Prices \\
\hline VI. & Foreign Trade \\
\hline VII. & World Review \\
\hline VIII. & Technology \\
\hline
\end{tabular}

topics as the structure of the domestic and foreign industries, byproducts and co-products, and strategic considerations. The publication also assessed the adequacy of world reserves to mect expected future demands. Table 2.3 gives a basic outline of the commodity chapters included.

Mineral Perspectives and Minerals Today delve more deeply into specific aspects of mineral and material markets. Mineral Perspectives reports on the mineral resources industries and related infrastructure of foreign countries and regions of the world that are of particular importance to U.S. minerals markets. Minerals Today covers selected minerals and materials and presents data and. analyses that are gerrnane to policy issues of current interest. 
Table 2.3 Basic outline of commodity chapters in Mineral Facts and Problems

\begin{tabular}{|c|c|}
\hline Summary & Byproducts and Coproducts \\
\hline Industry Structure & Strategic Considerations \\
\hline Background & Economic Factors and Problems \\
\hline Size and Organization & Prices \\
\hline Geographic Distribution & Capital Costs \\
\hline Definitions, Grades, Specifications & Tariffs \\
\hline Uses & Taxes \\
\hline Reserves-Resources & Depletion Provisions \\
\hline U.S. and World & Operating Factors and Problems \\
\hline Geology & Envir onmental Considerations \\
\hline Tochnology & Toxicity \\
\hline Exploration and Development & Energy Requirements \\
\hline Mining & Productivity Trends \\
\hline Processing & Outlock \\
\hline Products for Trade and Industry & Demand \\
\hline Current Research and Applications & End-use contingency forecasts, 1990 and 2000 \\
\hline Suppty-Dernand Relationships & Summary of forecasts, 1990 and 2000 \\
\hline Components of Supply & End-use trends \\
\hline Mine producticiil & Cumulative requirements to 2000 \\
\hline Imports of ore and concentrates & Adequacy of Supply \\
\hline Imports of metal and refined products & U.S. and world resources \\
\hline Stocks & Forecast production to 1990 a $\mathrm{d} 2000$ \\
\hline Old scrap & Twenty-year projection \\
\hline U.S. and World Production & Qualitative forecasts based on contingency analyses \\
\hline US. and World Consumption. & Possible Supply-Demand Changes \\
\hline World Trade & Possible Technology Progress \\
\hline Secondary Sources or Recycling & References \\
\hline Substitutes & Other Sources of Information \\
\hline
\end{tabular}




\section{THE DEFINITION AND CLASSIFICATION OF ADVANCED MATERIALS}

Bcfore the differences between advanced and traditional materials can be discussed and the implications of those differences for information requirements can be assessed, we must first discuss the definition of advanced materials and possible advanced materials classification schemes. Fraser, Barsotti, and Rogich (1988) present BOM's definition of advanced materials presented in U.S. BOM (1987):

Advanced materials are those developed over the past 30 years or so, and being developed at present, that exhibit greater strength, higher strength density ratios, greater hardness, and/or one or more superior thermal, electrical, optical, or chemical properties when compared with traditional materials. Advanced ceramics, metals, and polymers, including composites of these, offer the promise of decreased energy consumption, better performance at lower cost, and less dependence on imports of strategic and critical materials. (page 5).

Fraser, Barsotti, and Rogich goes on to identify six advanced material subgroups (page 5):

1. "metals and alloys" such as aluminum-lithium alloys, amorphous and shape memory alloys, rapidly solidified and porosity metals and ordered intermetallics;

2. "structural ceramics" such as alumina, silicon carbide and nitride, beryllia, boron nitride, titanium carbide, and thoria;

3. "engineering polymers" such as polyacrylate, polyetheretherketone (PEEK), polyphenylene sulphide (PPS), and a variety of polyamide-imides;

4. "advanced composites" using metal, ceramic, or polymer matrix containing particle, whisker and fiber reinforcements made of such things as carbon, boron, zirconia, aluminum silicates, and polymers;

5. "electronic, magnetic, and optical materials" such as gallium, indium, yttrium, zirconium, barium, lanthanum and the lanthanides; and 
6. "medical and dental materials" such as alumina and calcium phosphate glasses and carbon fibre reinforced polylactic acid composites.

The definition of advanced materials is also discussed in Riggs (1988) and Landsberg and Macauley (1988b). Riggs defines advanced materials as "materials with unique mechanical, thermal, optical, electrical, or inagnetic properties, and combinations of these, purchased for function and for added value derived from use" (page 37).

Landsberg and Macauley speak to the question of definitions with some skepticism:

As one reviews the literature, one seeks in vain for consistent, hard definitions. It seems to be one of those instances when everybody knows what the object of the investigation is as long as there is no request for a definition -- a situation not too unlike that of materials generally which are commonly described in some such way as "substances from which useful things are fashioned". Perhaps most striking is the dual-track approach in defining advanced materials. One is based on the physical or chemical characteristics of the materials, the other on the application or segment of the economy in which they are used. (page 9).

The authors go on to discuss the difficulty in deciding if a particular material is an advanced material according to either characteristics or applications. "Where to draw the line is no easy matter. Indeed, it may not be feasible" (page 9). The authors conclude that "...there is no such thing as a class or family of materials called "advanced materials" (page 12).

While it is very difficult to state a definition of advanced materials that is acceptable to all parties, the definition of advanced materials (or lack thereof) is nonetheless important in identifying information needs. Two general points are particularly relevant with respect to definitional problems. First, if a generaliy accepted definition of advanced materials cannot be agreed upon, the question of the aggregate impacts of advanced materials on, for example, traditional materials or the economy as a whole is not tractable. Authors often speculate that the size of the advanced materials market is growing at a particular rate or that advanced materials are displacing traditional materials in specific quantities. Clark and Flemings (1986) concluded that "The value of shipments of advanced materials is about $\$ 70$ billion, or approximately 14 percent of total materials shipments." However, if there 
is no such thing as a well defined class of materials that can be labeled "advanced," the impacts of advanced materials in the aggregate cannot be assessed.

Likewise, it is difficult to discuss policy issues as they pertain to the entire set of "advanced materials." To do so would presume that all "advanced materials" (1) present common problems that merit government involvement and (2) hold common properties that government measures could target. As will be discussed further in the following section, advanced materials differ from traditional materials in various ways -- including, but certainly not limited to, differences in physical and chemical properties and end-use applications. Not all advanced materials differ from traditional materials in the same ways, given that differences can occur in $r$ any dimensions. In fact, it can be argued that the difficulty in defining advanced materials results from our current inability to identify the numerous dimensions in which advanced inaterials can differ from traditional materials.

If a group of materials cannot collectively be defined as "advanced," it is all the more important that individual materials that carry the "advanced" label be defined and classified as precisely as possible (i.e., in terms of physical and chemical characteristics, end-use applications, and/or other relevant qualities). In addition, it is important that market assessments and policy analyses be done for individual advanced materials, in which the special qualities of those individual materials are recognized. The advanced materials market cannot be assessed as a whole until a consensus is reached on how advanced materials should be defined.

Second, our current inability to define advanced materials adequately suggests that different types of problems exist for different information users (e.g., industry representatives, technologists, hard scientists, social scientists, business analysts, and policy makers). Landsberg and Macauley (1988a) report the conclusions reached by participants in a workshop on advanced materials in which the problem of defining advanced materials was raised. "All in all, the industry participants showed themselves far less concerned over the absence of a satisfactory definition, or the existence of several 
competing ones, than did the economists" (pages 2 and 3). The authors suggest that technologists and industry participants "know what (they) are working with" (page 3). In other words, the most important qualities of "advanced materials" with which they work are physical and chemical properties, and those properties can be measured and manipulated. Technologists and hard scientists may appreciate "the value of obtaining data that describe the magnitude of the advanced materials' realm in quantitative ierms, but it is not a major concern.... By contrast the non-industry participants showed strong dissatisfaction with the absence of means that describe, in numbers, this segment of the materials world" (page 3).

A major implication of this second point has to do with categorizing advanced materials according to physical and chemical characteristics, according to applications, and/or according to other measurable qualities. Landsberg and Macauley (1988b) state that "In the advanced materials area,... the landscape is rich and orderly for the hard sciences, but arid and confusing for the social sciences. It all starts with the tedious matter of definition or classification" (page 2). It must be recognized that different disciplines have different interests with respect to advanced materials, and different interests suggest different classification schemes. For hard scientists, definitions and classifications according to physical and chemical properties may be most appropriate. This assertion is supported by the findings of the workshop reported in Landsberg and Macauley (1988a). Referring to the opinions of technologists, the authors state that "If there was any preference among those that spoke, it was for definition along physical/chemical lines as opposed to function, application lines..." (page 3).

For those more interested in business/social/policy questions, end market uses may be more appropriate. Landsberg and Macauley (1988b) use the example of silicon to argue that classification according to applications is most appropriate for business/social/policy assessments. "Silicon is probably the most prominent example of electronic materials as the hitherto major basis for semiconductors. Is silicon an advanced material then? In its natural form it is hard to think of it that 
way.... On the other hand, high-purity silicon has a variety of high-technology uses.... The point here is that silicon is or is not an 'advanced' material, depending wholly on the use" (pages 9 and 10). The authors go on to argue that "it is exceedingly difficult to approach any economic analysis from the materials end. Rather, the way to any kind of quantitative analysis of what is and of what might be is better undertaken from the application side, in the hope that a use-by-use review can yicld reasonable insights in terms of the relevant materials" (page 12).

For BOM, in its quest to disaggregate the advanced materials market in a tractable and useful way, advanced material classifications should be made according to the audience that is targeted to use the information provided. The selection of a target audience must be done on a material-by. material basis. It can be argued, however, that since the definitional problem is more severe for the soft sciences than the hard sciences, the classification of advanced materials should be more attuned to the needs of policy and market analysts.

If the classification scheme is more along application lines, a related problem concerns where to draw the line along the "processing trail." As will be discussed in more detail in the following section, it is often difficult to distinguish advanced materials from the products in which the materials are used. Further, advanced materials often begin as common elements that are not normally considered advanced. Therefore, it is often very difficult to establish front-end and back-end boundaries for advanced materials in terms of the processing steps that are involved. The example of silicon given above is a case in point. When, in terms of processing, does silicon change from a plentiful traditional material into an advanced material? Further, when does silicon used in electronic equipment change from an advanced material into a product?

While the establishment of when these changes occur may, by necessity, be somewhat arbitrary, it is important to recognize the problem when examining information needs. Boundaries should be established that allow trictable and meaningful analyses. On the one hand, classifications 
based on applications that are overly precise may not be consistent with available information, and the classifications may have to be altered frequently as technology evolves. In addition, too much disaggregation may lead to subcategories that are diffi-slt and costly to monitor and that may be of interest to few individuals. On the other hand, classifications that are overly general may lead to information that includes a wide range of advanced materials or some advanced and some traditional materials. In this case, the special characteristics and problems associated with advanced materials may not be tractable. Unfortunately, no classification scheme is applicable to all materials that carry the "advanced" label. The selection of a classification scheme must be made on a material-by-material basis and must take into consideration the BOM's target audience and the special characteristics/problems associated with the individual advanced materials.

Formulating a definition of advanced materials is of primary importance if one wishes to evaluate and present information on the "advanced materials" sector as a whole. We have argued, however, that advanced materials differ in numerous ways. These differences make it very difficult to define advanced materials to include particular sets of materials (while excluding others). It is, therefore, difficult and not particularly useful to discuss "advanced material" in the aggiegate. From BOM's perspective, the definition of advanced materials -- in terms of inaterial properties or in terms of end-use applications -. may be a significant point of debate, but is not of primary importance to BOM's data collection efforts or to potential users of BOM information.

What is of particular importance to both $\mathrm{BOM}$ and to users of $\mathrm{BOM}$ information is the classification scheme used to disaggregate the materials BOM decides to include in the somewhat vague class of materials called "advanced." Or, in other words, how should this class of materials be partitioned so that the information provided on the various parts is of greatest use? With respect to this second point, the issue of classification according to material properties or end-use applications is important. We have argued that classification according to properties is more appropriate for hard 
scientists. Classification according to end-use applications may be more appropriate for social scientists.

Given that the value of advanced materials in particular end-use applications is derived from the properties of those materials, the classification of advanced materials should, ideally, be made in terms of material properties. From the hard scientists' perspective, the benefits are obvious. From the sovial scientists' perspertive, it is more appropriate to study, for example, the value of specific material properties, rather than the value and potential size of groups of materials ... e.g., steel, copper, ceramics, etc. Unfortunately, social scientists are not particularly attuned to assessing the value and potential uses of material properties. As will be discussed in later sections of this report, methodologies are being developed, and to some limited extent used, to assess the value of and potential markets for material propertius. For example, hedonic demand approaches are moving economists in the direction of assessing properties of goods and materials.

Uniortunately, these approaches and the data to facilitate their use are in their infancies. A classification scheme based solely on material properties will lead to classifications and information that may be of little current use to social scientists. The issue for BOM thus becomes one for whom the BOM information is being targeted. If social scientists are in the target audience, end-use applications should be a part of the classification scheme. To satisfy the interests of both hard and social scientists, BOM should investigate the feasibility of classifying materials according to a combination of material properties and end-uses. While this classification scheme will lead to grater partitioning, the benefits may outweigh the costs. 


\section{FUNDAMENTAL DIFFERENCES BETWEEN ADVANCED AND TRADITIONAL MATERIALS AND IMPLICATIONS FOR INFORMATION NEEDS}

This section examines the fundamental differences between advanced and traditional materials and the implications of those differences on information needs. Twelve fundamental differences are identified, each of which is first discussed in conceptual terms. That discussion is followed by an example of the particular difference, and the implications of that difference for information needs are then assessed.

Because of the somewhat inexact nature of this exercise, the fundamental differences identified may in some cases overlap partially and are not exhaustive. Furthermore, the information needs are discussed in terms of the information that is already provided by BOM with respect to traditional materials. (See Section 2.) It is presumed that the information that BOM has historically collected on traditional materials is also relevant to advanced materials. In some cases a fundamental difference between advanced and traditional materials may imply that certain types of information usually provided on traditional materials should be more or less emphasized with respect to advanced materials. In other cases the fundamental difference may imply that a totally new type of information is needed. The recommendations for information needs are therefore discussed as marginal changes from what is currently collected on traditional materials, rather than an all-inclusive list of information needs for advanced materials.

The fundamental differences identified in this section do not apply to all advanced materials. In other words, it is not suggested that these fundamental differences are requirements for a material to be classified as advanced. Rather, this report suggests that advancer materials may differ from traditional materials in the ways discussed and argues the implications of those potential differences for information needs. 


\subsection{ADVANCED MATERIALS DISPLAY DIFFERENT PHYSICAL AND THEMICAL PROPERTIES - SOME OF WHICH ARE SUPERIOR AND SOME OF WHICH ARE INFERIOR TO TRADITIONAL MATERIALS.}

Advanced materials have historically been promoted on the basis of their superior physical and chemical properties. Unfortunately, the superior properties often come in combination with other properties that are inferior to those of traditional materials. For example, Kupezyk (1988) states that composices have various advantages including weight savings, good stiffness behavior, excell -nit surface quality, and cost efficient production. The author goes on to point out various disadvantages relating to reliability, maintainability, repairability, and producibility.

The first and most obvious implication of these physical and chemical differences is a need to (1) identify the physical and chemical characteristics most important to specific advanced materials and (2) provide data on those material properties. While BOM has not historically provided detailed information on physical and chemical properties, BOM could identify the properties that are most crucial for decision making and provide information on where additional data on material properties might be obtained.

Sundaresan (1988) argues that the typical engineer faces two main problems with advanced materials. The first is associated with known differences in the behavior of advanced materials, such as ductility, fatigue strength, wear resistance, or the material's response to creep and high temperatures. The second is the added complexity of new materials, and including a larger degree of variability in materials properties, differtnt sensitivities to manufacturing processes, anisotropy, and degradation of properties as a result of stress, temperature extremes, and fluid environments. Sundaresan also points out that standard conventional properties are not always applicable with advanced materials and that batch to batch variability in raw materials, manufacturing materials, and finished parts can cause engineers to distrust advanced materials. The uncertainties associated with material properties are obviously more pronounced with advanced materials. In addition, individuals 
are being forced to evaluate properties they have not heretofore considered. BOM could reduce these uncertainties by providing a "road map" to sources of information on material properties.

Second, the significantly different physical and chemical propertles displayed by advanced materials have implications for demand forecasting. Traditional approaches that examine the demand for a material without explicit consideration of the properties of that material may be inappropriate. Hedonic demand models, which examine the demand for material properties, are more appropriate tools for examining the demand for advanced materials and the potential substitution of advanced materials for traditional matcrials.

\subsection{THE RELATTVE IMPORTANCE OF INPUTS (I.E, HUMAN CAPITAL, PHYSICAL CAPITAL, LABOR, ENERGY, AND MATERIALS) IN THE RESEARCH, DEVELOPMENT, AND YRODUCTION OF ADVANCED MATERIALS MAY BE. SIGNIFICANTLY DIFFERENT.}

There is a general perception that the research, development, and production of advanced materials requires a significantly different mix of inputs than traditional materials do. In fact, advanced materials have been promoted in part on the basis of being less dependent on vulnerable materials. Hondros (1986) points out that advanced materials may substitute energy for materials. According to the author, future developments may allow virtually "everything from anything," given sufficient energy, Landsberg and Macauley (1988b) suggest that advanced materials secm to be more human capital or knowledge intensive and less labor and physical capital intensive. R\&D with respect to advanced materials may be relatively more dependent on physical capital than is the case with traditional materials because of the broad range of testing that must be done. Clearly, there is no one way in which advanced materials differ from traditional materials in terms of inputs. Most advanced materials are, however, less dependent on expensive and scarce material inputs. The relative importance of other inputs must be considered on a case-by-case basis. 
We can again look to sillicon as an example of this difference. Silicon in its natural form is both cheap and abundant. However, higta-temperature ceramics, such as silicon carbide and sillicon nitride, and much of the semiconductor and solar cell industries depend on purified forms of silicon. Obtaining these puriffed and expensive forms of silicon is not dependent on the material sillcon, but rather on other inputs: labor, energy, human capital, and physical capital. Most traditional materials, such as copper, are more dependent on the minerals themselves.

This difference has several implications for information needs. First, the notion of materials vulnerability is fundamentally different with those advanced materials that exhibit this basic difference. In general, the most significant input for most advanced materials is not the material, but rather the knowledge that makes the emergence of the material possible. Advanced materials are typically less dependent on materials and more dependent on intermediate products and processing technologies. Thus, the scarce resource is not a mineral but human ingenuity.

Vulnerability reducing measures, such as material stockpiles, take on new meaning. If stocks are to be maintained, those stocks must be intermediate products to offer security from foreign processors. Alternatively, stocks of knowledge and processing facilities can be maintained. The assessment of vulnerability with respect to advanced materials must therefore be discussed within a different framework. With traditional materials, the question of materials security is typically put in terms of material stocks. With advanced materials, security is more appropriately assessed in terms of available processing capacity and the country's ability to adjust quickly to cutoffs of intermediate supplies.

Second, following the first point, information on reserves and resources of raw materials is of less importance with most advanced materials. The production and consumption of the raw materials from which the advanced materials are made are also less important. Emphasis is needed on the resources that are of most importance to the advanced material of concern. When providing 
data on material inputs to an advanced material, care must be taken to identify the intermediate material on which the focus is most appropriate. For example, in the case of advanced polymers, basic chemicals such as benzene and ethylene are intermediate inputs. However, the availability of these common chemicals is not germane to a discussion about advanced material inputs because advanced materials under any realistic scenario will demand only a tiny percentage of total chemical production.

The appropriate intermediate material on which to focus for a class of advanced materials is an empirical question. Important factors to consider are (1) the size of the market for the intermediate material as compared with the quantity of that intermediate material demanded in the production of the advanced material of interest, (2) the capabilities of the domestic and foreign industries to increase production of the intermediate material as a function of time and price (i.e., the short-and intermediate-term elasticities of supply, and (3) the reliability of the source of the intermediate material.

Third, the difference in the importance of inputs has implications for the way foreign competition is assessed. The ability of a country to compete in international markets will, typically, be less dependent on materials and more dependent on physical capital, human capital, labor, and energy. The relative importance of these different inputs must be assessed for each advanced material. As pointed out in Marcum (1987), different countries will have different relative advantages with respect to different inputs. The question of which country has a relative advantage in the production of advanced materials must assess the relative importance of different inputs and the abilities of different countries to provide those inputs at lowest cost. For example, developing countries that have plentiful and cheap labor will have a relative advantage in the production of advanced materials that require significant quantities of labor. 
Fourth, a similar point can be made about industrial structure. Industrial structure (e.g., vertical and horizontal integration, concentration ratios) may depend on the relative importance of different inputs. Studies are needed to assess if there is an identifiable relationship between the relative importance of different inputs and the evolution of an industry's structure.

\subsection{THE RESEARCH, DEVELOPMENT, AND PRODUCTION OF ADVANCED MATERIALS REQUIRE A BROADER RANGE OF EXPERTISE AND SCIENTIFIC KNOWLEDGE THAN DO TRADITIONAL MATERIALS.}

This conceptual point and an example of the point are best made by quotation from a recent publication. "Many people are reluctant to use a new material because it is not within their frame of reference.... Processing changes the structure and properties of composites, and so design and materials selection are coupled. A designer must be a chemical engineer to understand how it is processed, and a mechanical engineer to design in it" (Compressed Air 1985).

The first implication of this point is the need to provide information that helps to bridge the gap among aisciplines. BOM could contribute to bridging this gap by summarizing the relevant issues for advanced materials according to disciplinary lines. The disciplines for which summaties are needed must be assessed on a material-by-material basis and will be a function of the technology used to produce and utilize the material. In addition to highlighting the disciplinary issues, the summaries should also direct the reader to additional information on that particular discipline for the selected advanced material.

Second, the complexity of advanced materials suggests that information is needed that summarizes various R\&D activities across all government agencies and in foreign research institutions. Additional information about unclassified R\&D activities in military agencies is particulariy needed, given the large amount of R\&D activity in the defense sector. 
Third, information is needed on training and education opportunities for cross-training in various relevant disciplines. Summary information on current R\&D and production collaborations that exist across government/industry/university boundaries would also be helpful.

Fourth, at least two interesting topics for special studies emerge from this fundamental difference. One concerns the effects of this difference on industry structure. Given that many advanced materials are a marriage of various materials and approaches, one might speculate that the development and production of advanced materials would lead to more collaboration among firms in order to obtain the needed expertise. Horizontal integration may also be promoted to obtain expertise that had heretofore not been rieeded. Vertical integration may be promoted to help ensure that the properties of the incoming inputs are acceptable for the application intended. The effects of antitrust laws, which discourage joint research and development activities, also need further assessment.

Another suggested special study concerns the role that different organizational structures play in cutting across organizational and disciplinary lines and thus facilitating the development and production of advanced materials. The effectiveness of small entrepreneurial units within firms that typically cut across organizational lines, such as those found in many Japanese firms, could be compared to the structures of many American entrepreneurial units that have fewer crossorganizational ties. One would hypothesize that units that cut across organizational and disciplinary lines would be more effective in the development and production of most advanced materials.

\subsection{ADVANCED MATERIALS EXHIBIT GREATER POTENTIAL FOR RAPID TECHNOLOGICAL ADVANCE AND MARKET PENETRATION THAN DO TRADITIONAL MATERIALS.}

Most advanced materials are in their infancy, and many advanced materials result from the combination of traditional materials and approaches. Different disciplines are being combined to mesh together skills and talents that have not heretofore been examined. Research and production 
are on learning curves that are very uncertain. Unlike most traditional materials, which are understood well and for which the technological frontiers are generally known, advanced materials offer the potential for rapid technological change in terms of material properties, manufacturing processes, and applications.

It is difficult to think of an advanced material that does not exhibit this basic difference. Advanced ceramics that become superconductive at relatively high temperatures are prime examples of rapid technological change. Composite materials, structural ceramics, and advanced polymers also are evolving rapidly and their potential applications are growing quickly.

This difference has several implications for information needs. First, rapid technological advance implies that the transfer of technology from the laboratory to the producer and consumer takes on new importance. Information is needed on technology transfer programs between the public and private sectors and between firms. University/industry relations become more important. Information is also needed on new patents and patent ownership, investment patterns in advanced materials, and consortium/cooperative research. Information on the availability of equipment at R\&D facilities, such as national laboratories, might be helpful. While BOM may not be able to directly promote the more rapid transfer of advanced materials technologies, additional information about the process and the barriers that must be overcome can indirectly promote the transfer process.

Second, the potential for rapid technological advance also offers the potential for rapid change in market dominance, both domestically and internationally. Assessments of international competition must consider not only the relative advantages of different economies to compete given current conditions, but must also speculate how technology will change and how those technology changes will alter the relative advantages of the various competing countries.

Third, supply/demand forecasting becomes particularly difficult when rapid technological change is observed. Most methodological approaches to supply/demand forecasting requile a constant 
industry structure. When rapid technological change occurs the industry structure also changes, and thus, most traditional approaches are not applicable. Most traditional approaches estimate the historical relationships between the various factors that are assumed to impact supply and demand and then project future supply and demand on the basis of those historical relations. Technological change implies that those historical relationships are not applicable to future time periods. The relative merits of alternative methodologies should be assessed in light of this problem. Landsberg and Macauley (1988a) suggest that approaches such as Fisher-Pry techniques, Delphi techniques, and "rules of thumb" need investigation.

Fourth, rapid technological change can also lead to rapid changes in industry structure. An argument can be made that rapid technological change will promote vertical integration to facilitate the rapid transfer of information about production processes. The effects of rapid technical change in advanced materials on industry structure should be examined both conceptually and empirically.

\subsection{PROPERTIES OF ADVANCED MATERIALS CAN BE CUSTOMIZED}

A recent article in Mining Journal (1988) statr: that "Rapid technological progress has made it possible to design a product first and then empivy the requisite technology to develop new materials rather than simply modifying existing ones" (page 246). The Office of Technolog; Assessment (1988) states that "with tailored materials, the old concept of materials, design, and fabrication processes are merged together into the new concept of integrated design and manufacturing" (page 10). Balazik and Klein (1987) state that "The creation of new materials atomby.atom is a significant departure from the conventional sequence of extraction, purification, and combination" (page 2).

Composite materials offer a good example of this basic difference. Composites of various types are designed to provide characteristics for customized applications (e.g., car panels to hightemperature heat exchangers). For example, continuous-fiber, ceramic-matrix composites are being 
designed to accommodate the high temperatures and pressures of advanced, high-pressure heat exchangers.

This basic difference is relevant to some of the information suggestions made in previous subsections, such as the need for better and more reliable information on material properties and the need for better coordination among R\&D facilities. The difference also has other implications. The most obvious implication for information needs concerns the distinction between advanced material and final product. Tegart (1985) suggests that computer modeling will permit the design of useful materials structures of great sophistication. If materials can be customized product by product, the categorization of advanced materials becomes all the more difficult.

General information on the degree to which a class of advanced materials can be customized is needed. Information of this type might appropriately fit within the context of what BOM has historically done in the area of traditional material technologies.

Customization also makes supply and demand forecasting more difficult. The need for approaches such as hedonic modeling, which focus on the demand and supply of material properties rather than materials per se, becomes more pronounced when this basic difference between advanced and Iraditional materials is noted.

\subsection{THE FABRICATION OF ADVANCED MATERIALS IS GENERALLY MORE DIFFICULT THAN IS THE CASE WITH TRADITIONAL MATERIALS.}

Various processing steps are required in the production of advanced and traditional materials -- i.e., raw materials recovery, refining, upgrading, fabrication, assembly, end-use, and recycling. With respect to many advanced materials, the fabrication step is often more difficult than is the case with most traditional materials. Sorrell (1987) and Mining Journal (1988) argue that fabrication is often the major technical barrier to commercial applications of advanced materials. Busch and Clark (1988) suggest that the fabrication process can become quite complex and can 
include several stages of fabrication. "(T)here is a group of businesses that produces semifabricated raw materials, for example, graphite/epoxy prepregs, seamless stainless steel tubing, niobium-titanium superconducting wires and gallium-arsenide crystal wafers" (page 4). Other examples of prefabrication include weaving or knitting of fabric broadgoods for advanced composites.

The main point of this difference for information needs concerns the relative need for information on fabrication. Given that fabrication is the acknowledged bottleneck in the production of most advanced materials, information about technology should focus primarily on the fabrication step. Information about R\&D activities in the area of fabrication would also be useful.

Studies should be done to determine the relative importance of other processing steps. The Office of Technology Assessment (1988) suggests that, for example, assembly is less complex and costly for advanced materials. Given that the technologies to produce and use advanced materials are complex, BOM's information on technology should forcus on those processing steps that pose the greatest concerns for technologists, as well as policy analysts. The processing step of greatest concern is an empirical question and must be assessed on a material-by-material basis.

\subsection{SOME EVIDENCE SUGGESTS THAT THE ECONOMIES OF SCALE IN THE PRODUCTION OF ADVANCED MATERIALS MAY' BE LESS THAN IN THE PRODUCTION OF TRADITIONAL MATERIALS.}

Landsberg and Macauley (1988b) point out that advanced materials are usually produced on a small scale in comparison to traditional materials. The requirement of tailoring advanced materials to meet the specific needs of end-users precludes mass fabrication and thus significant ecoromies of scale. Such is the case with most advanced composites and plastics. (Economies of scale refer to the range of production over which long-run average cost declines. For most goods, diseconomies of scale are eventually reached as the size of the plant and the scale of operations become larger.) 
Limited economies of scale do not, however, appear to be the case with some intermediate advanced materials. For example, there is currently only one producer of high-purity silicon in the United States. While cursory evidence suggests that economies of scale decrease as an advanced material's production moves downstream, those economies of scale need to be assessed on a materialby-material basis.

The main implication of this potential fundamental difference is for forecasting future industry structure and international competitiveness. As an industry for an advanced material matures, the size and number of firms in that industry will be a direct function of the economies of scale associated with the product being produced. The degree to which U.S. producers of advanced materials will be competitive in international markets will also, in part, be a function of scale economies. Special studies are needed to assess the degree to which scale economies exist in the production of advanced materials and the effects of those scale economies on industry structure and international competitiveness.

Work is also needed to suggest how scale economies may change as probable future technological breakthroughs are realized. What are the economies of scale with respect to major classifications of advanced materials? Further, are those economies expected to arise because of specialization of labor or because of technological factors? Supply modeling is particularly sensitive to what is assumed about scale economies.

\subsection{THE PRODUCTION OF BY-PRODUCTS IS LESS COMMON WITH ADVANCED MATERIALS}

Some of the raw materials that are used in the production of advanced materials are actually by-products of the production of traditional materials. Such is the case with yttrium, which is used in most of the new, high-temperature superconducting ceramics. Lands'oerg and Macauley (1988b) point out that yttrium is a by-product in the production of uranium and phosphates. Numerous other 
examples can be cited. There are few cases, however, where the production of advanced materials leads to the production of by-products.

Two implications emerge for information needs from this basic difference. First, there is less need for emphasis on by-products from the production of advanced materials. Second, and a corollary to the first point, there is a need for greater emphasis on by-products from the production of traditional materials.

By-products production is particularly important in understanding the relationship between traditional and advanced materials. The availability and costs of some advanced materials are inextricably linked to the production of traditional materials. Therefore, projections of raw material resources ana supplies of raw materials required for some advanced materials must consider what is likely to happen in the traditional materials market; and what happens in the traditional materials market may depend heavily on what happens in the advanced materials market. Because of these interrelationships, projections based on systems of equations are needed.

\subsection{THE POTENTIAL FOR RECYCLING ADVANCED MATERIALS IS MORE LIMITED THAN IS THE CASE WITH MOST TRADITIONAL MATERIALS.}

Advanced materials exhibit several qualities that make them more difficult to recycle than traditional materials. First, they are produced in relatively small quantities and are often dispersed widely, making collection difficult and costly. Second, advanced materials are often customized for particular applications; and, in general, the more customized the material, the more difficult the recycling of that material becomes. It is therefore difficult to collect large quantities of an advanced material with uniform properties; and recycling of commingled advanced materials with heterogeneous properties is likely to pose significant technical constraints. Third, advanced materials are often combinations of diffent materials which are meshed together in a way that makes separation of the component materials both difficult and costly. Fourth, the raw materials used to manufacture 
advanced materials are often of low value. Therefore, even if the component materials can be separated, the value of those materials would make the economics of the venture unattractive. Recycling operations would therefore need to recycle the advanced material in its high-tech form, l.e., the output of the recycling process would have to exhibit the special properties of the original advanced material. Technical problems make that a very difficult task.

Composites are the best example of the problems posed by recycling advanced materials. They are usually made in small quantities, with specialized properties; they are extremely difficult to separate; and their component materials are not of great value. Advanced plastics and advanced ceramics also exhibit these same qualities.

The primary implication of this basic difference has to do with the way recycling is assessed by BOM. The recycling of many traditional materials (e.g., steel, aluminum, and copper), has a significant impact on supplies of raw materials. Environmental concerns are of lesser importance. With most advanced materials, recycling has little or no implications for the available resource base. Currently, environmental concerns must be the primary focus of any recycling assessment.

The inability to recycle most advanced materials will also have implications for life-cycle costs, which are discussed below. A less tractable but possibly important implication has to do with the public"s perception of advanced materials. If advanced materials are acknowledged as non-recyclable, public pressure may limit their use. There will also be pressure at a policy level to impose taxes on advanced materials to account for the higher social costs imposed by advanced materials because they are difficult to recycle. 


\subsection{THE ENVIRONMENTAL CONSEQUENCES OF THE PRODUCTION, USE, AND/OR DISPOSAL OF ADVANCED MATERIALS MAY DIFFER SIGNIFICANTLY FROM THOSE OF TRADITIONAL MATERIALS.}

The different materials used, the different processing, and the difficulty in recycling advanced materials may significantly alter the environmental implications of producing, using, and/or disposing of advanced materials. Clark and Flemings (1986) state that "The manulacture of ceramic and composite materials may entall the dispersion of particles. Although the carcinogenic effects of these malerials on human beings have not been documented, the smallest libers used in the production of high-performance ceramics have been shown in controlled laboratory studies to give tise to tumors in the lung lining of animals" (page 57).

Basic information is needed on how the environmental effects of a class of advanced materials may differ from traditional materials. Such inforrnation is crucial in assessing worker and product liabilities and in assessing the public's potential reaction to a growing market for advanced materials. Information on environmental consequences is also required to assess the life-cycle costs of advanced materials.

\subsection{THE LIFE-CYCLE COSTS AND BENEFITS OF ADVANCED MATERIAIS DIFFER SIGNIFICANTLY FROM THOSE OF TRADITIONAL MATERIALS.}

Riggs (1988) argues that advanced materials are often not adopted because of a failure to understand the potential cost impacts on the total system. The Office of Technology Transfer (1988) suggests that "The new tailored materials require a new paradigm. The materials and the end products made from them become indistinguishable, joined by an integrated design and manufacturing process. This necessitates a closer relationship among researchers, designers, and production personnel, as well as new approaches to the concept of materials costs" (page 15). OTA suggests that advanced materials may, in particular, exhibit lower assembly costs and longer service lives. OTA further suggests that "...end-users (of advanced materials) must take advantage of potential savings 
In fabrication, installation, and life-cycle costs to offset the higher materials costs: in other words a systems approach to costs is required" (page 17). The costs and benefits structure for advanced materials differs from that of traditional materials for various steps of production, use, and disposal. An assessment of the economic viability of an advanced material must include all steps during the life of the material.

The main implication of this difference has to do with the emphasis placed on different types of cost information. Although cost information of the types historically provided on traditional materials by BOM is relevant to advanced materials, that information can be misleading if not presented within the context of life-cycle costs. Life-cycle costs must also be considered when making supply/demand projections for advanced materials.

One special study that is particularly relevant to the need for life-cycle costs has to do with how markets for advanced materials may assess the varying cost/benefit structure. Consider the analogy of high-efficiency appliances. High-efficiency appliances typically cost more when installed, but cost less in terms of fuel expenses over the life of the appliance. Studies have examined how consumers evaluate the altered cost/benefit structure presented by high-efficiency appliances. [See, for example, Hausman (1979).] Most of these studies conclude that consumers use an unusually large discount rate when making decisions about high-efficiency appliances. In other words, consumers heavily discount the future benefits they expect to receive in terms of fuel savings.

Similar problems may arise with respect to the adoption and use of advanced materials. Advanced materials may appear favorable when considered on a life-cycle cost basis in which a "reasonable" discount rate is used. The advanced materials may nonetheless not be adopted, implying that either a higher discount rate is used, that accurate information is not being conveyed to all producers and consumers irivolved, or that market mechanisms are such that the true benefits of the advanced material cannot or are not adequately transferred from one party to the next in terms of 
the production and/or use of the naturial. For example, purchasers of automoblles that employ highfuelefficiency technologies typically utilize high discount rates. When one considers, however, that the typical owner of a new car keeps that car only about three years, and that the ability of the original purchaser to recoup the added Initial investment is uncertain, the higher discount rates can be explained. Similar problems may arise with respoct to advaneed materials. The degree to which such problems may distort supply and demand projections is a relevant cmpirical questlon and ls worthy of a special study by BOM.

\subsection{HISTORICAL DATA ON ALL ASPECTS OF ADVANCED MATERIAIS IS QUITE LIMITED}

Although not a fundamental difference that will last indefinitely, there is currently a void of historical information on all aspects of advanced material markets. The lack of historical information will force new methodological approaches to be used to forecast most of the market parameters that BOM has historically provided for traditional materials. Case studies on similar advanced materials and Delphi techniques may be useful.

The Mining Journal (1988) argues that the virtual absence of historical data on consumption of advanced materials makes it difficult to measure the impact that advanced materials will have on traditional material industries. Questions exist about where advanced materials have made inroads thus far -- i.e., substitution for traditional materials or new and unique uses?

Landsberg and Macauley (1988b) suggest that case studies of advanced materials may shed light on how the demand and supply of other advanced materials may behave. With respect to supply and production costs, are there general learriag economies whereby production costs fall as total cumulative production increases? Are there thresholds to these learning economies? Scale 
economies and joint and by-product production must be considered. The assessment of motivation for development and adoption, speed of adoption, the roles of the public and private sectors, technical incentives and obstacles, and the role of serendipity may be helpful in assessing future markets for advanced matcrials with almilar characteristics.

Now demand approaches will be required. Hedonic domand approaches, which focus on the demand for material propertics rather than materials themselves, have already been mentioned. Single equation methods may be of limited value. Systems of equations and alternative demand specification may help incorporate the linkages between advaneed and traditional materials. Demand as a function of price will obviously differ greatly from matcrial to material and from application to application. For example, advanced materials used primarily in military applications will be quite inclastic .. l.e., quantity demanded will not be very sensitive to price changes. Demand may also be inelastic in those cases where the cost of the advanced material represents only a small fraction of the total cost of the end product.

The lack of historical data in combination with continuing structural change in the markets for advanced materials will force analysts to use alternative and innovative methodologies. The particular methodology chosen will depend on the specific characteristics of individual advanced material markets.

\subsection{SUMMARY}

Table 4.1 summarizes the twelve fundamental differences identified in this section that distinguish advancec materials from traditional materials. The table also summarizes the implications of those differences for information needs and analyses. In summarizing these information needs, recall that it is presumed that the information currently collected and published on traditional materials is also needed for advanced materials. The suggestions for information needs and analyses are given as marginal changes from what is currently provided on traditional materials. 


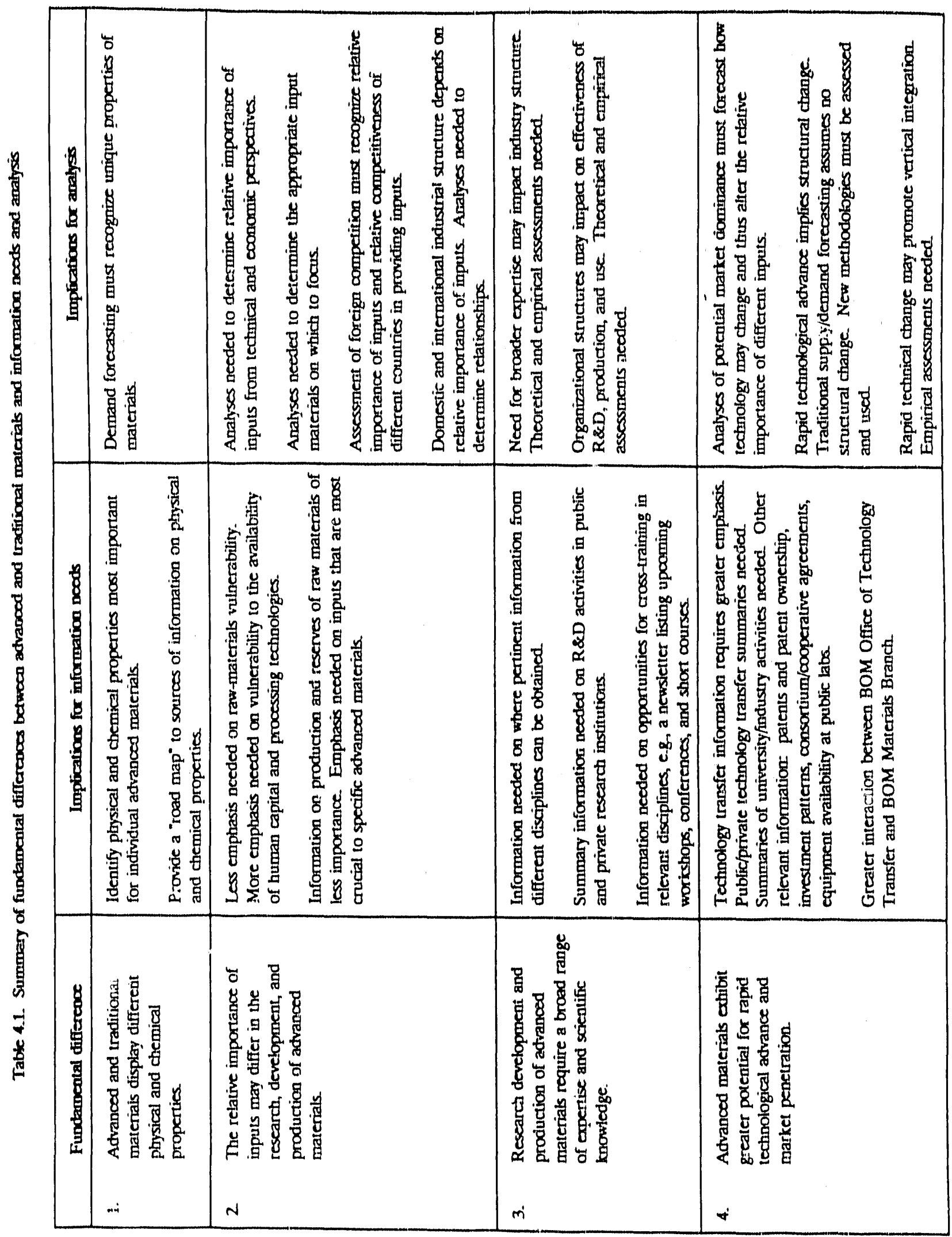




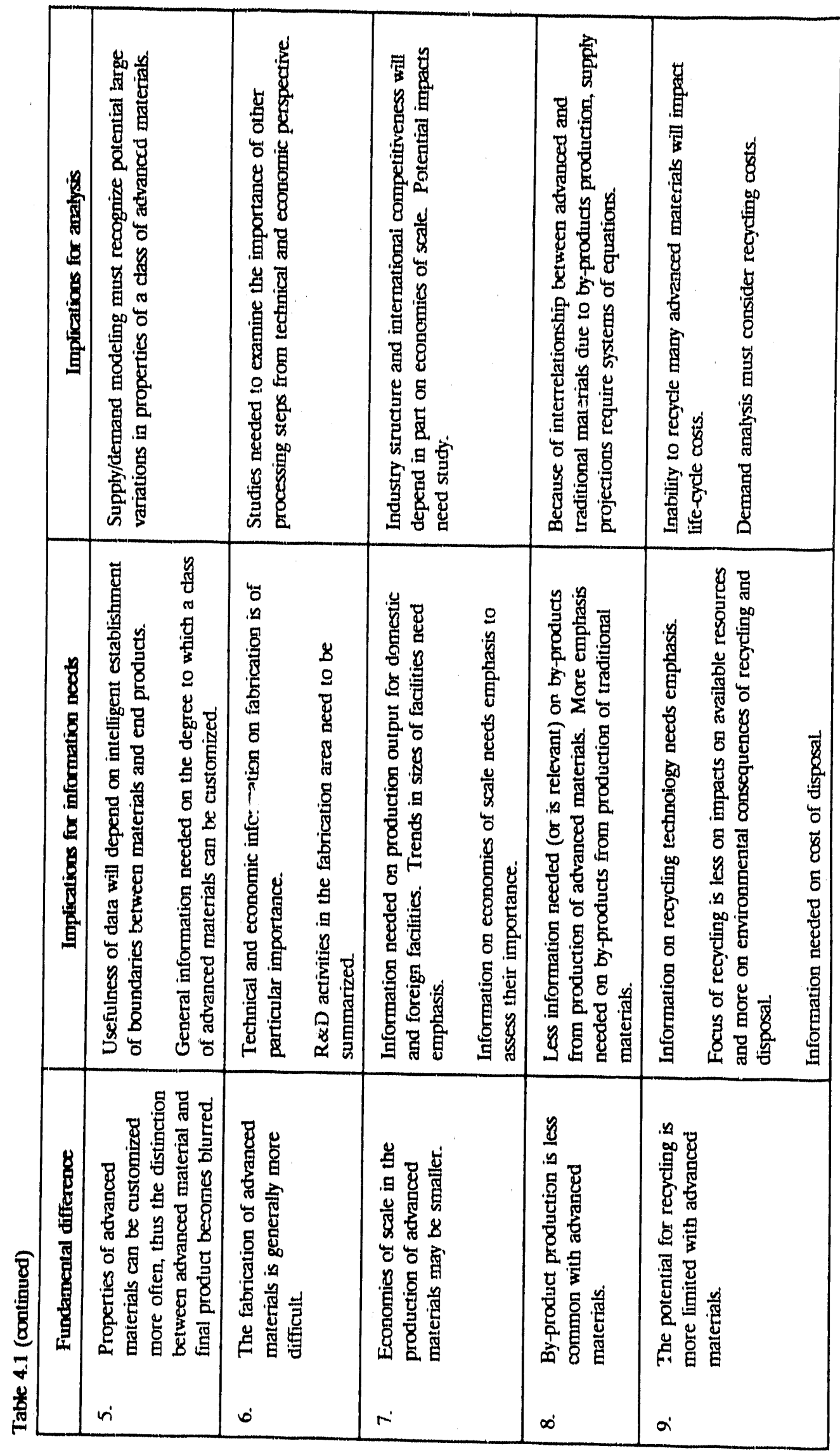




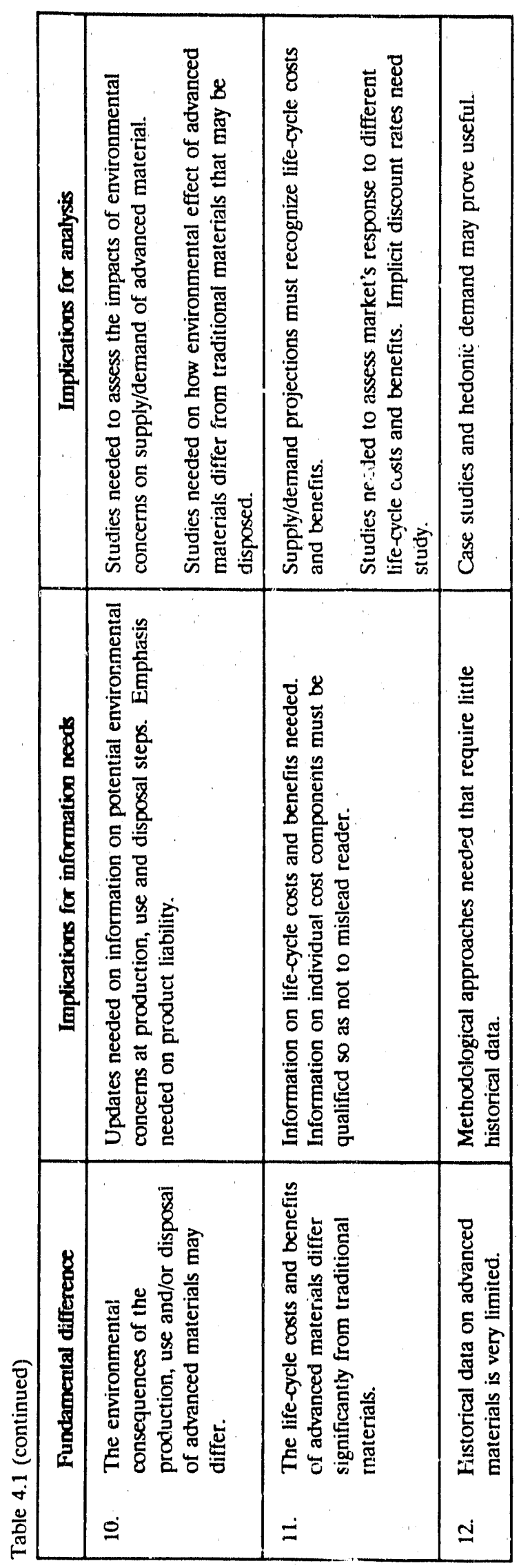


There are several overriding themes to the differences. Advanced and traditional materials differ significantly in terms of physical and chemical properties. Advanced material properties can be customized more often. The production of advanced materials may differ from traditional materials in terms of inputs, the importance of by-products, the importance of different processing steps (especially fabrication), and scale economies. The potential for change in advanced materials characteristics and markets is greater and is derived from the marriage of radically different materials and processes. The cost/benefit structure over the life of the material may be very different for advanced materials, suggesting that traditional measures of a material's economic viability may not be applicable.

The implications of these fundamental differences for information needs and analyses also follow several themes. There is currently a need for "road maps" to direct interested individuals to detailed sources of physical, chemical, and market data. There is a need to establish meaningful boundaries for advanced materials in terms of input materials and products -- i.e., when in the processing chain does a material become advanced, and when does an advanced material become a product? Finally, in many cases the categories of information needed with respect to advanced materials are the same as with traditional materials. However, the primary focus of those general categories may differ sharply (e.g., materials vulnerability). Identifying information needs and analyses for advanced materials requires a fundamental rethinking of why informaticn of various types is important and to whom and for what purposes that information may be useful. 


\section{RESULTS OF THE QUESTIONNAIRE}

\subsection{INTRODUCTION}

Previous sections of this report have discussed the definition, classification, and fundamental characteristics of advanced materials. Fundamental differences between advanced and traditional materials also were discussed, along with the implications of these differences. This section discusses a questionnaire entitled "Advanced Materials: Information Needs, Sources and Analysis," which was designed and implemented by the Energy Division of Oak Ridge National Laboratory (ORNL) to assess the opinions of potential users of information on advanced materials. The questionnaire serves to (1) assess the degree to which the views stated in our Section 4 are shared by potential users of information and (2) identify the advanced materials, information needs, and issues of greatest importance to our sample of respondents. A sample questionnaire is listed in Appendix A. The number in parentheses beside each question indicates the number of respondents for a particular question or response.

\subsection{QUESTIONNAIRE DEVELOPMENT}

The questionnaire was developed after extensive review of the literature on differences between traditional and advanced materials. Discussions with the BOM staff also helped in the development of the contents in the questionnaire. Several people provided useful comments on preliminary drafts. Professor William Lyons, a political scientist with the University of Tennessee, Knoxville, assisted in the structural design and implementation of the questionnaire. BOM staff and several scientists from ORNL's Metals and Ceramics Division provided useful comments regarding the technical accuracy and the contents of the questionnaire. 


\subsection{DESCRIPTION OF SAMPLE POPULATION}

BOM provided the list of names and addresses of the sample population. A majority of the sample population consists of people who either attended or were notified about the BOM' conference entitled "Advanced Materials: Outlook \& Information Requirements," held in Alexandria, Virginia, on November $7-8,1989$. This conference was designed for a wide audience of materials professionals, including engineers, economists, scientists, policy analysts, consultants, and market researchers. The first day of the conference featured a series of overview briefings that showed how technology is changing the world of materials. On the second day of the conference, implications of the changing world of materials for the government's materials information programs were described. A small portion of the sample population is composed of the current subscribers to the BOM's various publications who were selected as potential users of the information on advanced materials. The questionnaire was sent to 934 people who were given one month to complete and return it.

Thus, the sample population chosen for the questionnaire represents potential users of the information, although it may not be a valid statistical sample representing various segments of the sample population, nor of all potential users of information on advanced materials. The sample is judgmental, but in our subjective opinion it represents the views of most potential users of information on advanced materials.

\section{$5.4 \quad$ RESULTS}

\subsubsection{Response Rate of the Sample}

The overall response rate was $20.2 \%$ (189 out of 934 people to whom questionnaires were sent). Table 5.1 gives an employment breakdown of respondents. A majority of respondents are producers of advanced materials. Federal agency employees constitute the next largest group. Other significant categories of respondents are public and private research and development employees, accounting for $21 \%$ and $22 \%$ of the total respondents, respectively. By job classification, most of the 
respondents are either managers or technical personnel, each accounting for $25 \%$ of the total respondents. The next several subsections discuss in detail respondents' views on several important aspects of advanced materials.

\begin{tabular}{||l|c|c||}
\hline \multicolumn{3}{|c|}{ Table 5.1 Employment breakdown of respondents } \\
\hline \multicolumn{1}{|c||}{ Employment } & Number & Percentage \\
\hline Producer & 42 & 22 \\
\hline Federal agency employee & 38 & 20 \\
\hline Public research and development employee & 22 & 12 \\
\hline Private research and development employee & 21 & 11 \\
\hline Supplier of raw materials & 9 & 5 \\
\hline Consumer & 8 & 4 \\
\hline Sales/marketing firm employee & 3 & 2 \\
\hline Supplier of equipment & 2 & 1 \\
\hline State agency employee & 2 & 1 \\
\hline Journalist & 1 & 1 \\
\hline Other* & 41 & 21 \\
\hline
\end{tabular}

\subsubsection{Definition of Advanced Materials}

Figure 5.1 shows respondents' opinions about the components that are important to the definition of advanced materials. The components considered are greater strength; higher strength/density ratios; greater hardness; and superior thermal, electrical, optical, and chemical properties. These are taken from the BOM's definition of advanced materials. The degree of 

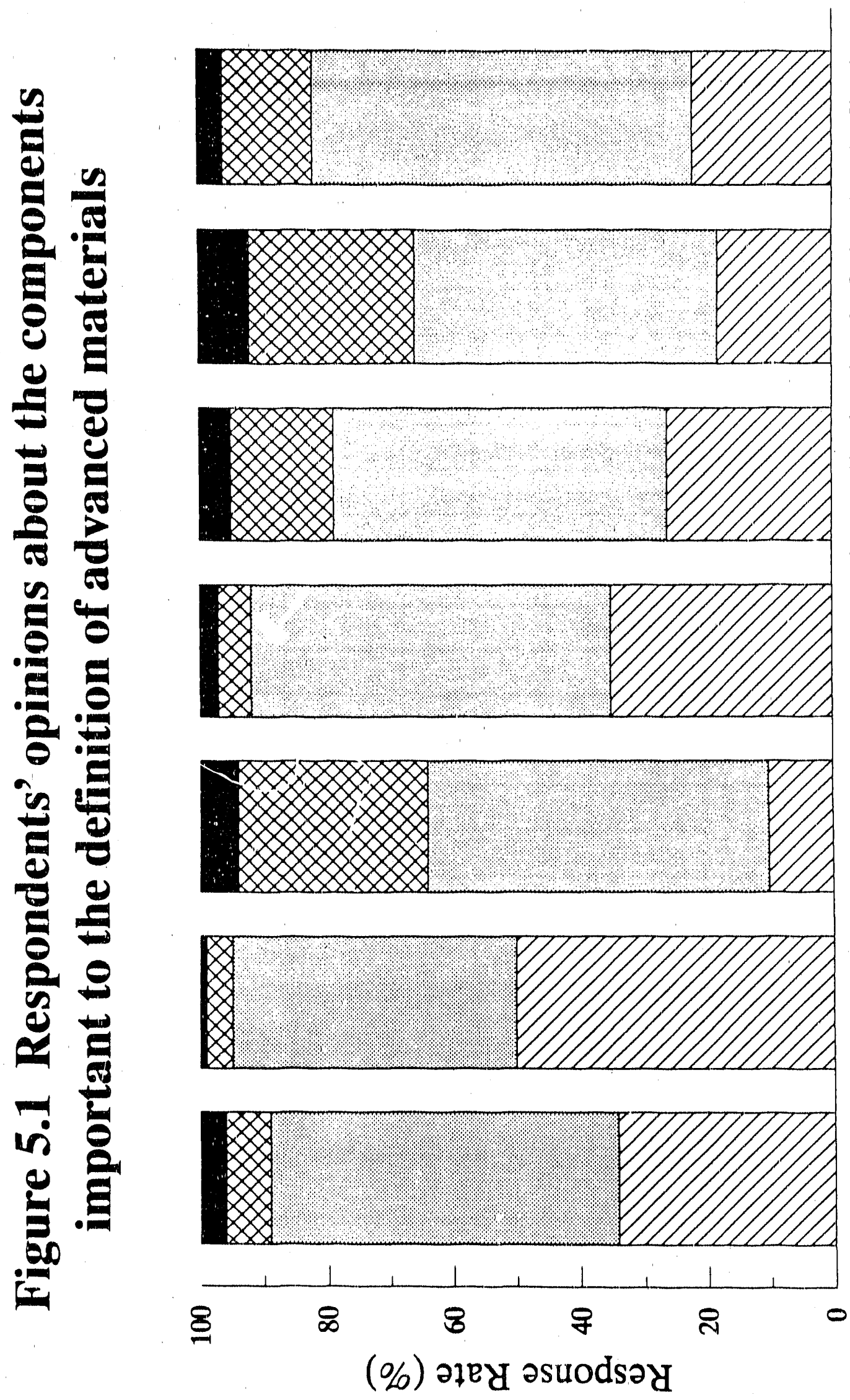

$\frac{0}{3}$

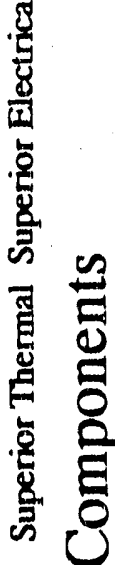

造

事

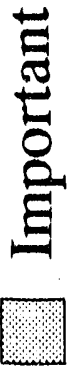

Е 
importance is expressed by four different choices in the following descending order of importance: essential, important, unimportant, and shouldn't include.

A majority of respondents think that all the given components are important to the definition of advanced materials. For each of these seven given components, at least $62.5 \%$ of the respondents agree that these components are either essential or important to the definition. The higher strength/density ratios component is considered the most important to the definition of advanced materials by the majority of respondents. Greater hardness and superior optical properties are the only two components that a significant number of respondents consider to be not importa't. Thirly five percent of the respondents think these components are either unimportant or shcruldn't be included in the definition.

Respondents' opinions about the importance of various components to the definition do not change significantly based on either their occupation or type of organization to which they belong. All components are considered important to the definition. All respondents, except nontechnical and research and development (R\&D) people consider higher strength/density ratios to be the only "essential" component of the definition.

Not all respondents think that the given components include all the ones important to the definition of advanced materials. About $50 \%$ of the respondents listed additional properties that should be included in the definition. These additional properties included fracture toughness, intended use or application, machinability, cost, corrosion resistance, and fabricability etc., and their inclusion in the responses varied by educational and/or occupational background of respondents. Quite a few respondents feel that fracture toughness and intended use or application need to be included additionally to the given definition. 


\subsubsection{Advanced Materials Categories}

Table 5.2 shows what respondents consider to be the most important advanced materials category. Composite engineering polymers and structural metals are the most important categories to many of the respondents. Absorptive metals, magnetic functional devices and structural and

\begin{tabular}{||l|c|}
\hline \multicolumn{2}{||}{ Table 5.2 Most important advanced materials category to respondents } \\
\hline Composite engineering polymers & 36 \\
\hline Structural metals & 33 \\
\hline Electronic and optical functional devices & 18 \\
\hline Composite structural ceramics & 17 \\
\hline Monolithic structural ceramics & 16 \\
\hline Structural engineering polymers & 15 \\
\hline Composite metals & 12 \\
\hline Magnetic functional devices & 2 \\
\hline Absorptive metals & 1 \\
\hline Structural medical and dental & 1 \\
\hline Functional medical and dental & 0 \\
\hline Other* & 38 \\
\hline Total & 189 \\
\hline $\begin{array}{l}\text { *Includes 28 respondents who did not identify their most important } \\
\text { advanced materials categories. }\end{array}$ \\
\hline
\end{tabular}

functional medical and dental categories of advanced materials were relatively unimportant. Table 5.3 categorizes specific advanced materials within a given advanced materials category in the descending order of interest to respondents. For example, under structural metals, superalloys are of most interest to the respondents and shape-memory alloys are of least interest. 
Table 5.3 Descending order of interest to the respondents for varlous subcatcgories within 11 inajor groups of advanced matorlals

A. Structural Metals

1. Superalloys

2. Titanlum Alloys

3. Surface Hardoned and Coated Mctals

4. Aluminum-Lithlum Alloys

5. Ordered Intermetallics

6. Superfine Particles"

6. Rapidly Solidified Alloys*

8. Amorphous Alloys

9. Copper*Berylllum Alloys

10. Shape Memory Alloys

B. Absorptive Metals

1. Hydrogen Storage Alloys

2. Porosity Mctals

C. Metal Comprasites

1. Whiskers

2. Oxides or Carbide Reiuforcements in Metal Matrices

3. Particulates

D. Monolithic Structural Ceramics

1. Oxides

2. Non-oxides

E. Compasite Structural Ceramics

1. Reinforcements in Matrices of Oxides \& Non-oxides

2. Carbon Matrix/Carbon Fiber Composites

F. Structural Engineering Potymess
1. Thermoplastics
2. Thermosets
3. Polymer Blends
4. Liquid Crystal Polymers
5. Polyurethane Foam

G. Compasite Engineering Polymers

1. Fiber/Whisker Reinforcements in Thermosets*

2. Fiber/Whisker Reinforcements in Thermoplastics*
H. Electronic and Optical Functional Devices

1. Superconductors

2. Semiconductors

3. Dlelectries*

3. Optical Fibers"

5. Piezoelectrics

6. Ferroclectrics

7. Light Emitters*

7. Ionic Conductors*

1. Magnetic Functional Devices

1. Motallic

2. Coramic

J. Structural Medical and Dental

1. Alumina Structures

2. Hydroxyapatite

3. Carbon Fiber/Polylactic Acld Composites

K. Functional Medical and Dental

1. Acrylics

2. Silicone*

2. Fluoropolymers*

- Represents a tie. 
Table 5.4 shows that the importance attributed to an advanced materials category depends on the respondent's occupation and his or her type of organization. Table 5.2 and 5.4 differ in that the former considers only a single category most important to the respondent whereas the latter table considers the respondent's attitudes about each category. The nature of Importance is indicaled by three choices: very important, somewhat important, and not important. Tuble 5.4 gives the cholee that was sclected most frequently by the respondents for each advanced materials category. Two symbols in any position in the table indicate a tie in the frequency of the cholees. The first three columns under "Respondents" include three types of occupation (i.c., manager, technical, and nontechnical), which are aggregates of several job classiffeations mentioned under question 13 in the questionnaire. The manager group Includes corporate managers and managers in federal or state agencies; the technical group includes geologists, mining engineers, manufacturing/process engineers, engineers (other), materials scientists, chemists, and technicians; and the nontechnical group includes economists, social scientists, accountant/financial analysts, lawyers, and policy analysts. The last three columns under "Respondents" include three types of organizations (i.e., producers and consumers, government employees, and research and development employees), which are aggregates of several employment categories mentioned under question 12 in the questionnaire.

Government employees include both federal and state employees. Research and development employees represent private as well as public organizations. The fourth column under "Respondents" represents the view of the total sample and thus helps in comparing opinions of individual categories within the two major classifications of respondents (i.e., type of occupation and type of organization) against the total sample. A few respondents do not either represent any of the three groups under each major classification or did not belong to any of the specific types of occupations and types of organizations listed in the questionnaire; thus, the summation of percentages of people in the three different categories within each major classification does not add up to 100\%. For example, under 
Table 5.4 Degree of importance attributed by respondents to various advanced materials

\begin{tabular}{|c|c|c|c|c|c|c|c|c|}
\hline \multirow{3}{*}{\multicolumn{2}{|c|}{ Advanced Malurials }} & \multicolumn{7}{|c|}{ Respundentsab } \\
\hline & & \multicolumn{3}{|c|}{ Type of Occupallon } & \multirow{3}{*}{$\frac{\text { Tolal }}{0}$} & \multicolumn{3}{|c|}{ Type of Organlzallon } \\
\hline & & \multirow{2}{*}{$\frac{\mathrm{Mgr} .}{0}$} & \multirow{2}{*}{$\frac{\text { Tech. }}{0}$} & \multirow{2}{*}{$\begin{array}{r}\text { Non } \\
\text { lech. }\end{array}$} & & \multirow{2}{*}{$\begin{array}{l}\text { Prod.1 } \\
\text { Cons. } \\
0\end{array}$} & \multirow{2}{*}{$\frac{\text { GovI }}{0}$} & \multirow{2}{*}{$\frac{R \& D}{6}$} \\
\hline A. & Structural Molals (Superalloys) & & & & & & & \\
\hline B. & $\begin{array}{l}\text { Absorplive Metals (Hydrogen } \\
\text { Storage Allouss) }\end{array}$ & 0 & 0 & $\theta$ & 0 & 0 & 0 & 0 \\
\hline $\mathrm{C}$ & $\begin{array}{l}\text { Composile Metals (Sllicon } \\
\text { Carbide/Nilrlde Reinforcemonis } \\
\text { in Melal Maltix) }\end{array}$ & - & $\theta$ & $\bullet$ & - & $\otimes 0$ & - & $\theta$ \\
\hline D. & $\begin{array}{l}\text { Monollthic Structural Ceramias } \\
\text { (Oxides and Non.Oxides) }\end{array}$ & $\bullet$ & 0 & $\theta$ & $\theta$ & 0 & e & 8 \\
\hline E. & $\begin{array}{l}\text { Composile Siructural Ceramlas } \\
\text { (Sillicon Carblde/Nitride } \\
\text { Reinforcemenis in Oxides and } \\
\text { Non-Oxides) }\end{array}$ & $\bullet$ & 0 & $\Leftrightarrow$ & $\bullet$ & 0 & - & - \\
\hline$F_{1}$ & Siructural Englneering Polymers & - & - & (3) & - & - & $\otimes$ & 0 \\
\hline 0. & $\begin{array}{l}\text { Composile Englneering Polymers } \\
\text { (Flber Reinforcomenis in } \\
\text { Thermoplastle and Thermosel } \\
\text { Resins) }\end{array}$ & - & - & $\theta$ & - & - & - & - \\
\hline$H$ & $\begin{array}{l}\text { Electronic and Opilcal Functional } \\
\text { Devices (Dielecirias, Ferro. } \\
\text { clectria and Superconductors) }\end{array}$ & 0 & 0 & 0 & 0 & 0 & ? & $\otimes$ \\
\hline 1. & $\begin{array}{l}\text { Magnelic Functional Devices } \\
\text { (Powder Alloys and Ferriles) }\end{array}$ & 0 & 0 & $\otimes$ & 0 & 0 & $\otimes$ & 0 \\
\hline $\mathrm{J}$ & $\begin{array}{l}\text { Siructural Medical and Dental } \\
\text { (Hydroxyapalle, Carbon Fibers) }\end{array}$ & 0 & 0 & 0 & 0 & 0 & 0 & $c$ \\
\hline$k$. & $\begin{array}{l}\text { Functional Medical and Dental } \\
\text { (Fluoropolymers, Acrylic Resins) }\end{array}$ & 0 & 0 & 0 & 0 & 0 & 0 & 0 \\
\hline 1 & $\begin{array}{ll}\text { Mgr.: } & \text { Manager (35s } \\
\text { Tech.: } & \text { Technical (35 } \\
\text { Nonlech.: } & \text { Nontechnical } \\
\text { Tolal: } & \text { Tolal Sample }\end{array}$ & & & $\begin{array}{l}\text { Prodl } / C \\
\text { Oowl: } \\
\text { R\&D: }\end{array}$ & $\begin{array}{l}\text { Pro } \\
\text { Gor } \\
\text { Res }\end{array}$ & $\begin{array}{l}\text { er/Consut } \\
\text { ament }(20 \\
\text { ch \& Dev }\end{array}$ & $\begin{array}{l}(26 \%) \\
\operatorname{men}(23 \%)\end{array}$ & \\
\hline b & - Very Importani & $\otimes$ & ewhat & ortant & & Nol $1 \mathrm{mp}$ & & \\
\hline
\end{tabular}


the type of organization classilfeation, $16 \%$ of respondents belonged to organizations different from the ones listed in the questlonnaire; and $5 \%$ of respondents did not Identify their type of organization.

All groups of respondents consider structural and composite enginecring polymers important. Comparatively new advanced materalas like electronic devices, optical and magnetic functional devices, medical and dental (both structural and functional) materials are considered the least important, at least among the sampled respondents. The future interest in these materials may be underestimated in our sample. Many of these materials have only recently $b_{2}+$ commercialized, but they are expected to be of growing significance in the future. For the other materials categories, there are differences based on respondents' occupational and organizational backgrounds. Structural metals are important to nonmanagerial respondents. Absorptive metals are "somewhat important" to only nontechnical respondents. Technical and producer and consumer respondents are not interested in structural ceramics; their lack of enthusiasm may be a result of the reliability and fabrication problems faced by structural ceramics. Magnetic functional devices are "somewhat important" to policy analysts.

Because of the differences in the two tables, structural engineering polymers show relatively more importance in Table 5.4 than in Table 5.2. Table 5.2 indicates that structural engineering polymers are not considered by many to be their most important category. Nevertheless, Table 5.4 indicates that they are considered as being "very important."

As compared to other groups, respondents from government organizations assign "very important" to the largest number of advanced materials categories, and producer and consumer respondents to the least number of categories. Respondents from government organizations represent one of two 
groups with an interest in optical and magnetic functional devices. Given that producers and consumers are averse to risk, they seem mainly interested in advanced matorials such as polymers, where technical barricrs are comparatively less severe.

\subsubsection{Difforencas Detween Traditional and Advanced Materials}

There are fundamental differences that may distinguish advanced materials from traditional materials. Table 5.5, which is structured similarly to Table 5.4, shows respondents' vicws about what statements they think are useful in distinguishing advanced materials from traditional materials. Respondents' views are expressed by any one of the four different cholecs in the following decreasing order of agreement: strongly agree, agree, disagree, and strongly disagree.

With few exceptions, there are no strong opinions ("strongly agree" or "strongly disagree") among various respondent groups on statements distinguishing advanced materials from traditional materials. For example, all but nontechnical respondents agree that advanced matcrials are less dependent on supplies of strategic materials and more dependent on processing technologies than are traditional materials. In general, respondents agree that advanced materials are more vulnerable to disruptions in raw materials, but not to intermediate products and processing technologies imported from other countries. The exceptions in this regard are government employees, who do not agree that advanced materials are vulnerable to disruptions of raw materials. This difference of opinion may be the result of the government respondents' way of looking at raw materials from a minerals point of view rather than as processed raw materials (e.g., ceramic powder).

\subsubsection{Issues and Problems}

Table 5.6 shows respondents' opinions about the importance of issues and problems associated with the production and use of advanced materials. Opinions are expressed by one of three choices: not a problem, a minor problem, and a major problem. 
Table 5.5 Differences between traditional and advanced materials

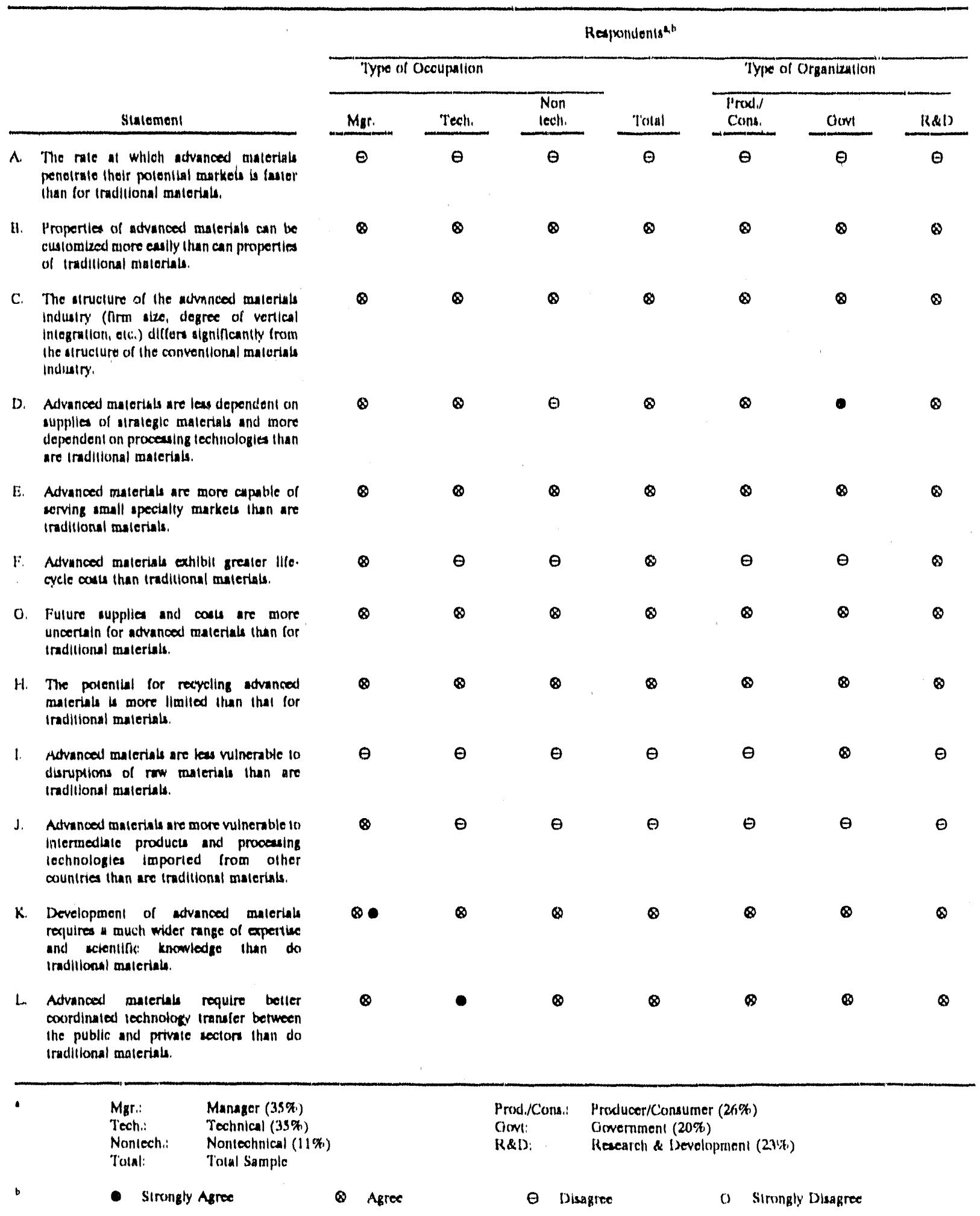


Table 5.6 Opinions about important issues and problems faced by the increased use of advanced materials

Respondents, ha

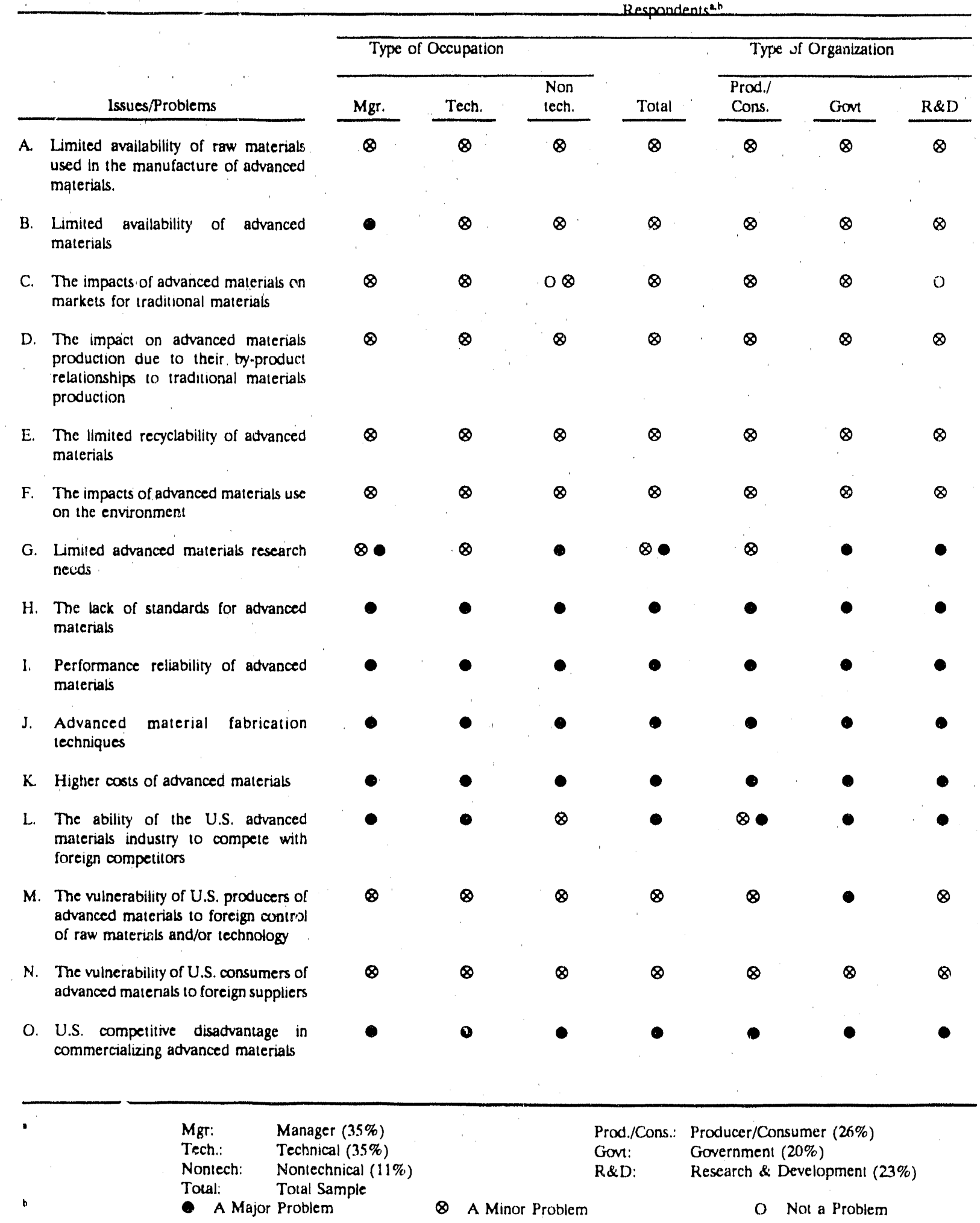


All different groups of respondents are in agreement on most issues and problems listed in Table 5.6. The lack of standards for advanced materials, performance reliability of advanced materials, advanced material fabrication techniques, higher cost of advanced materials, the ability of the U.S. advanced materials industry to compete with foreign competitors, and the U.S. competitive disadvantage in commercializing advanced materials are considered to be the major problems brought about by the advanced materials industry. Somewhat lesser problems are (1) limited availability of raw materials used in the manufacture of advanced materials, (2) recyclability and (3) environmental concerns.

Some groups of respondents differ from the majority. For example, nontechnical respondents do not think that the impacts of advanced materials on markets for traditional materials is a problem, while the population as a whole does. The issue of vulnerability of U.S. producers of advanced materials to foreign control of raw materials and/or technology is identified as a major concern only for government employees.

\subsubsection{Information Needs}

There is interest in obtaining various types of information for different categories of advanced materials, as shown in Table 5.7. The level of interest for specific needs is qualified in terms of one of three choices: great interest, moderate interest, and no interest. In this table, absorptive metals, magnetic functional devices, and structural and functional medical and dental materials are not included. These categories of advanced materials were not considered important by a vast majority of respondents as noted in Table 5.2. The different types of information are listed in the left-most column, and the advanced materials categories are listed across the top of the table. Table 5.7 shows, for a particular advanced materials category, the level of interest in each information category shared by the majority of respondents who consider that particular advanced material to be the most important. 
Table 5.7 Interest in obtaining the types of information for various categories of advanced materials

\begin{tabular}{|c|c|c|c|c|c|c|c|c|}
\hline & Information & $\begin{array}{c}\text { Structural } \\
\text { Metsls }\end{array}$ & $\begin{array}{l}\text { Composile } \\
\text { Metals }\end{array}$ & $\begin{array}{l}\text { Monolithic } \\
\text { Structural } \\
\text { Ceramics } \\
\end{array}$ & $\begin{array}{l}\text { Composite } \\
\text { Structural } \\
\text { Ceramies } \\
\end{array}$ & $\begin{array}{l}\text { Structural } \\
\text { Engineering } \\
\text { Polymers }\end{array}$ & $\begin{array}{l}\text { Composite } \\
\text { Engineering } \\
\text { Polymers } \\
\end{array}$ & $\begin{array}{l}\text { Electronic } \\
\& \text { Optical } \\
\text { Functional } \\
\text { Devices } \\
\end{array}$ \\
\hline A & $\begin{array}{l}\text { Industry structure (e.g., size, } \\
\text { distribution, specifications) }\end{array}$ & - & $\otimes$ & - & - & 8 & 0 & $\otimes$ \\
\hline B. & Uses of the material & $\dot{0}$ & - & ○ & - & ○ & - & - \\
\hline C. & $\begin{array}{l}\text { Raw materials for advanced } \\
\text { materials }\end{array}$ & 8 & $\otimes$ & $\otimes$ & 8 & $\theta$ & 8 & $\otimes$ \\
\hline D. & Current technology & - & - & - & - & - & - & 0 \\
\hline E. & Technology outlook & - & - & - & - & 8 & 0 & ○ \\
\hline F. & $\begin{array}{l}\text { Supply/demand relationships } \\
\text { (including imports, exports, } \\
\text { stocks) }\end{array}$ & 0 & - & 8 & - & $\otimes$ & $\otimes$ & 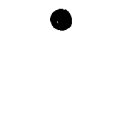 \\
\hline G. & Demand forecasts & 0 & - & - & $\theta$ & - & - & - \\
\hline $\mathrm{H}$. & Supply forecasts & $\otimes$ & - & 8 & $\otimes$ & $\otimes$ & $\theta$ & $\otimes$ \\
\hline I. & Byproducts and coproducts & 8 & $\otimes$ & Q & 8 & 8 & $\otimes$ & $\otimes$ \\
\hline 了. & Strategic considerations & (8) & $\bigcirc$ & 0 & 8 & $\otimes$ & - & $\otimes$ \\
\hline K. & $\begin{array}{l}\text { Economic factors and problems } \\
\text { (e.g., prices, costs of production) }\end{array}$ & 0 & - & ? & - & 8 & - & - \\
\hline L. & $\begin{array}{l}\text { Operating factors and problems } \\
\text { (e.g., loxicity, environmental } \\
\text { considerations, energy } \\
\text { requirements) }\end{array}$ & 6 & - & ? & $\otimes$ & $\otimes$ & ? & $\otimes$ \\
\hline M. & $\begin{array}{l}\text { Legislation and government } \\
\text { programs }\end{array}$ & 8 & ? & (2) & - & $\otimes$ & 0 & - \\
\hline & Properties of the material & ○ & - & O & - & - & - & 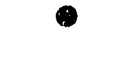 \\
\hline
\end{tabular}


Properties of the materials, uses of the materials, current technology, technology outlook, prices, and costs of production are the types of information that respondents have great interest in obtaining. Composite metals and composite engineering polymers are the two categories for which respondents have the greatest interest in obtaining different types of information. There is the least interest in structural enginecring polymers compared to other materials included in the table.

Somewhat less interest was expressed in information on broader economic and political issues, such as industry structure, supply and demand forecasts, strategic considerations, and legislation and government programs, although the level of interest was still moderate to great, depending on the matcrial. For example, information on legislation and government programs is most desired for composite metals, composite structural ceramics, compositc engineering polymers, and electronic and optical functional devices. Information on raw materials, by-products, and coproducts is of somewhat less interest for all categories of advanced materials.

\subsubsection{Information Use}

Information on advanced materials can be used for supply/demand/projections, sales/marketing, policy analysis, and production and consumption decisions, etc. It is important not only to know how the various types of information would be used, but also the frequency and level of use. Table 5.8 shows the relative use in different uses of information (listed in the left-most column) for different categories of advanced materials. The interest in different uses of information is represented by one of three choices: would use, would not use, and might use. The frequency (daily, weekly, or monthly) and the level of information use (raw data, summary statistics, projections, etc.) are also shown in this table. This information is given in general terms for each advanced material category and is not specific to each of the various uses of information.

Respondents show an overwhelming preference for using information for technical research and development. This is consistent with the respondents' desire for information on properties and technology. Respondents may view advanced materials as being in their early stages of development. 
Table 5.8 The use of information for various categories of advanced materials

\begin{tabular}{|c|c|c|c|c|c|c|c|c|c|}
\hline & & & $\begin{array}{l}\text { Structural } \\
\text { Metals }\end{array}$ & $\begin{array}{l}\text { Composite } \\
\text { Melult }\end{array}$ & $\begin{array}{l}\text { Momollitic } \\
\text { Structural } \\
\text { Cerremica }\end{array}$ & $\begin{array}{l}\text { Componile } \\
\text { Structural } \\
\text { Ceramics }\end{array}$ & $\begin{array}{l}\text { Siructural } \\
\text { Eingiseeriag } \\
\text { Polywers }\end{array}$ & $\begin{array}{l}\text { Composile } \\
\text { Eagineering } \\
\text { Polywers }\end{array}$ & $\begin{array}{l}\text { Wecironic } \\
\text { \& Optical } \\
\text { Punctional } \\
\text { Devices } \\
\end{array}$ \\
\hline \multirow[t]{7}{*}{ A. } & & $\begin{array}{l}\text { SE OF } \\
\text { MATION USE } \\
\text { ( Would use; } \\
\otimes . \text { Might use; } \\
\text { O: Would nol use) }\end{array}$ & & & ' & & & & \\
\hline & 1. & $\begin{array}{l}\text { Supply/demand/price } \\
\text { projections }\end{array}$ & $\bullet$ & - & 8 & $\otimes$ & - & $\bullet$ & $\theta$ \\
\hline & 2. & Sales/marketing & $\circ \bullet$ & $\otimes$ & - & $\otimes$ & - & $\bullet$ & $\circ$ \\
\hline & 3. & Policy analysis & $\otimes$ & $\otimes \bullet$ & 8 & 0 & $\otimes$ & 8 & - \\
\hline & 4. & Producilon decisions & $\otimes$ & - & $0 \bullet$ & $\otimes$ & - & $\otimes$ & 0 \\
\hline & 5. & Consumplion decisions & $\otimes$ & $\bullet$ & $\otimes$ & 8 & $Q$ & 8 & 0 \\
\hline & 6. & $\begin{array}{l}\text { Technical research and } \\
\text { development }\end{array}$ & $\bullet$ & - & - & - & - & $\bullet$ & 0 \\
\hline B. & & $\begin{array}{l}\text { JENCY OF } \\
\text { MATION USE } \\
\text { (D: Once a day; } \\
\text { W: Once a week; } \\
\text { M: Once a month) }\end{array}$ & $M$ & W M & $\mathrm{D}$ & $\mathrm{D}$ & $\mathrm{D}$ & $D M$ & $W^{\prime}$ \\
\hline C. & & $\begin{array}{l}\text { OF } \\
\text { MATION USE } \\
\text { (P: Projections; } \\
\text { S: Summary statustics) }\end{array}$ & $S$ & $P$ & $S$ & $S$ & $\mathrm{~S}$ & $S$ & s \\
\hline
\end{tabular}


Broader issues like production, consumption, and marketing decisions appear to be of less interest at this stage.

Somewhat less interest was expressed in using information for production, consumption, sales, and marketing decisions (the use varies depending on the material). There appears to be the least interest in using information for policy analysis. Individuals most interested in composite metalswould use information in most ways listed. Information on electronic and optical functional devices would be mostly used for supply/demand/price projections and policy analysis.

Respondents most interested in structural ceramics and engineering polymers suggest that they will use information on a daily basis. For all other categories of advanced materials, respondents expect to use information on a weekly or monthly basis. There are two cases (i.e., composite metals and composite engineering polymers) in which respondents plan to use information on both a frequent and infrequent basis. Respondents prefer to have information in summary statistics form for most categories. 


\section{RESULTS OF THE QUESTIONNAIRE AND CONCEPTUAL ASSESSMENT: COMPARISONS AND RESOLUTIONS OF DIFFERENCES}

Section 3 of this report discusses the problems that arise in defining and classifying advanced materials. Section 4 discusses potential fundamental differences between advanced and traditional materials and the implications of those differences for information needs. The results of our questionnaire are presented in the previous section. In many cases, the questions asked in the questionnaire closely parallel the major points made in Sections 3 and 4. In this section, comparisons are made between the conceptual points made in Sections 3 and 4 and the empirical points derived from the questionnaire. In drawing these comparisons, we first review the conceptual points from Sections 3 and 4 that are addressed directly or indirectly in the questionnaire. We follow this discussion with a comparison of the results from the questionnaire. In those cases where conflicts appear to exist between the conceptual conclusions and the results of the questionnaire, we attempt to resolve the differences.

\subsection{POINTS LEADING FROM THE DISCUSSION OF DEFINITIONS AND CLASSIFICA- TION SCHEMES}

Section 3 draws several conclusions that are discussed indirectly in the questionnaire. First, the section suggests that advanced materials are difficult to define and classify because of a lack of consensus on whether emphasis should be placed on physical and chemical properties, on end-use applications, or on other relevant parameters. While a vast majority of the respondents to the questionnaire agree that the physical and chemical properties listed in the BOM's definition of advanced materials are important to the definition, $50 \%$ of the respondents listed one or more additional parameters they believe to be important to the definition. The BOM definition and probably any other definition would not be completely acceptable to the respondents. 
Second, the conceptual discussion suggests that a classification scheme based on end-use applications may be more appropriate if the target audience is composed of "soft scientists." Classifications based on physical and chemical properties are more important for "hard scientists." Most of the respondents to the questionnaire are hard scientists and, interestingly, the sample as a whole considered the advanced material categories based on end-use applications to be least important. However, one must be careful not to read more into this observation than is warranted. The questionnaire did not present classification schemes for the same advanced materials based on end-use applications and on physical and chemical propertics. Therefore, general conclusions cannot be drawn. Follow-on work might further investigate the preference for classification schemes based on end-use applications as compared to physical and chemical properties.

\subsection{POINTS LEADING FROM FUNDAMENTAL DIFFERENCES BETWEEN ADVANCED AND TRADITIONAL MATERIALS}

\subsection{Advanced and Traditional Materials Differ in Terms of Physical and Chemical Properties}

Section 4 suggests that advanced and traditional materials differ significantly in terms of physical and chemical properties. That difference calls for more information on material properties and on where detailed data on properties can be obtained. As seen in Figure 5.1, most respondents agree that certain properties are usually important to the definition of advanced materials. In general, there is great interest in having information on properties of advanced materials. The questionnaire poses two other questions directly relevant to this conceptual observation. The first asks if the lack of standards for advanced materials poses problems for advanced materials use. Respondents overwhelmingly agree with the assertion that the lack of standards is a problem -- $62 \%$ listing it as a major problem and an additional $31 \%$ listing it as a minor problem. The second question asks if performance reliability of advanced materials is a problem. Again, respondents agree - $54 \%$ listing it as a major problem and $34 \%$ identifying it as a minor problem. 


\subsubsection{Advanced and Traditional Materials Differ in Terms of the Importance of Capital, Labor, Material, and Energy Inputs}

Section 4 suggests that differences in the relative importance of inputs between advanced and traditional materials can lead to several implications for information needs. For example, as compared to traditional materials, many raw materials used to produce advanced materials are readily available. An assessment of advanced materials vulnerability is most appropriately focused on processing technology and intermediate products, rather than raw materials. A follow-on to this point is that advanced materials require less emphasis on rescrves of raw materials.

The questionnaire poses several questions relevant to these assertions. Some $88 \%$ of questionnaire respondents believe that the limited availability of raw materials used in the manufacture of advanced materials is either not a problem or is only a minor problem. Thus, without distinguishing where raw materials are located, respondents do not believe availability of those materials is a serious problem. With respect to the vulnerability of raw materials for advanced materials production, the questionnaire results are somewhat dubious. Respondents are split between agreeing and disagreeing with the statement that advanced materials are less vulnerable to disruption of raw materials than are traditional materials -. 56\% disagreeing or strongly disagreeing with the statement and $44 \%$ agreeing or strongly agreeing. It is interesting to note that with respect to this question, a majority of the respondents from the government sector agree with the statement, while a majority of all other respondents disagree.

The results are more definitive when we pose questions that compare the vulnerability of advanced materials to disruptions in raw materials supply, to vulnerability resulting from the availability of processing technologies. Some $71 \%$ of respondents agree or strongly agree with the statement that advanced materials are less dependent on supplies of strategic materials and more dependent on processing technologies than are traditional materials. When we examine the response to this statement in terms of groups, we find that a majority of government respondents strongly 
agree; non-technical respondents actually disagree with the statement; and the remainder of our subgroups identified in Table 5.5 simply agree with the statement.

Taking the question of vulnerability one step further and posing the statement that advanced materials arc more vulnerable to intermediate products and processing technologies imported from other countries than are traditional materials, the responses once again become dubious. Some $45 \%$ of the respondents agree or strongly agree with the statement, while 55\% disagree or strongly disagree. Note that a majority of the manager group agrees with the statement and is an outlior in our sample.

Finally, when respondents were asked about the severity of problems posed by the vulnerability of U.S. producers of advanced materials to foreign control of raw matcrials and/or technology, $30 \%$ listed the problems as major and an additional $49 \%$ listed the problems as minor. A majority of the government subgroup listed the problems as major.

What can we conclude from these various questions and responses? First, the availability of raw materials used in the production of advanced materials is not viewed as a problem. Second, the majority feels that, while resources of raw materials are adequate, advanced materials are vulnerable to disruptions in supplies of raw materials m although the consensus is not overwhelming. Third, respondents generally agree that advanced materials are more vulnerable to not having processing technologies than to supplies of raw materials. Finally, respondents from the government view raw materials vulnerability to be less severe and vulnerability to processing technologies to be more severe than the sample population as a whole.

\subsection{The R\&D and Production of Advanced Materials Require a Broader Range of Expertise and Scientific Knowledge than do Traditional Materials}

Respondents generally agree with this assertion. About $91 \%$ of respondents agree with the statement that development of advanced materials requires a much wider range of expertisc and scientific knowledge than do traditional materials. Suggestions for summary information on R\&D 
programs across various research organizations and types, as woll as on training and educational programs, seem to be supported by the findings of the questionmaire.

\subsection{As Compared to Traditional Matorials, Advanced Matorials Have the Potontial for More Rapid Technological Advances and Markot Ponotration}

Respondents generally disagree with the assertion that advaneed materials penctrate markets laster than do traditional materials. About $73 \%$ disagree or strongly disagree with the assertlon that the rate at which advaneed materials penetrate their potential markets is faster than for traditional materials. It should be noted, however, that the wording of the assertion in the questionnalie and the wording of the assertion in Section 4 are diflerent. The conceptual section asserts that advanced materials have the potential for rapid market penetration. The questionnalre asserts, and the respondents disagrec, that advanced materials do penetrate faster ... which is suggestive of historical observation. The discrepancy between our concoptual and empirical findings are worthy of further investigation.

Respondents do agree with an implication of our conceptual point. About $82 \%$ agree or strongly agree with the assertion that advaneed materials require better coordinated technologry transfer between the public and private sectors than do traditional materials. A majority of respondeats with technical backgrounds strongly agree with the assertion, while other groups simply agree. Suggestions for better and more complete information on R\&D and patent activities as they pertain to advanced materials seem to be supported by the questionnaire's findings.

\subsection{Advanced Materials Can Be Customized More for Specific Applications Than Can Traditional Materials}

Respondents generally agree with the assertions put forth in the conceptual scction. About $64 \%$ of the respondents agree or strongly agree with the assertion that properties of advanced materials can be customized more easily than can properties of traditional materials. Some 80\% agree or strongly agree with the statement that advaneed materials are more capable of serving small 
specialty markets than are traditional materials. The responses tend to support the recommendation that information be provided on the extent to which classes of advaneed materials can be customized. Respondents recognize the numerous and varied uses that some advanced materlals may have, which points to the importance of selecting a materlals classiffeation scheme that incorporates these varied uses.

\subsubsection{The Fabrication of Advaneed Materials Is Gencrally More Diflicult than is the Case with Traditional Materials}

Recommend atons for a technology focus on the fabrication step are supported by the questionnaire findings, Some $73 \%$ of respondents list advanced material fabrication techniques as a major problem. Another $23 \%$ of the respondents list the problem as minor.

\subsection{Raw Materials for Advanced Materials May Be Crucially Linked to the Production of By- Products from Traditional Materials Manufacture}

Our conceptual section suggested that the production of advanced materials seldomly leads to the production of valuable by-products. However, the raw materials used in the production of advanced materials are sometimes produced as by-products in the manufacture of traditional materials. Information on this interrelationship between advanced and traditional materials was identified as crucial in assessing and forecasting the price and availability of resources for the production of many advanced materials.

Questionnaire results do not, however, support these general findings and ecommendations. Information on by-products and co-products are only of moderate interest to most respondents. Further, about $91 \%$ of all respondents believe that the impacts on advanced materials production due to their by-product relationships with traditional materials products are either not a problem or are only a minor problem. These results can be attributed partially to the advanced material categories found to be most important to the respondents. The number of respondents in different advanced material categories were not uniformly represented. Advanced metals are probably most dependent 
on by-products from traditional material production. However, only $29 \%$ of the respondents listed advanced metals as most important to them among the advanced material categorles listed in Table 5.2. Ceramics and polymers are most important to $52 \%$ of the respondents, and these advanced materials are not, in general, dopendent on by-products from the production oi traditional materials.

\subsubsection{Advanced Materials May Significantly Affect Markcts for Traditional Materials}

Questions exist about whether advanced materials will displace a signilicunt pereentage of the traditional materials market or simply be employed in applications not currently served by traditional materials. BOM's focus on this potential displacement must be considered on a case-by-case basis, and with some advanced materials significant displacement can be expected.

Respondents do not, however, believe that advaneed materials will impose major impacts on traditional material markets. Approximately $84 \%$ of all respondents believe that the impacts of advanced materials on markets for traditional materials will not be a problem or will be only a minor problem.

\subsubsection{Advanced Materials Are More Dilficult to Recycle than Are Traditional Materials}

Our conceptual section gives various reasons why advanced materials may be more difficult to recycle than traditional materials. This basic difference implies that BOM should focus on recycling of advanced materials not in terms of the effects of recycling on the resource base, but rather in terms of technological and economic constraints to recycling and the potential cnvironmental impacts of advanced materials disposal.

Respondents generally agree with our assertions, although not strongly. Some $68 \%$ of respondents agree or strongly agree with the statement that the potential for recycling advanced materials is more limited than that for traditional materials. However, when asked to list the degree 
to which the limited recyclabillty of advanced materials is a problem, 53\% list the problem as minor, $24 \%$ suggest recyclability is not a problem, and $23 \%$ list the problem as major.

\subsubsection{The Environmontal Consequences of Producing, Using, and Disposing of Advanced Materials May Diffor Significantly from Traditional Matorials}

Our conceptual section suggests that environmental differences between advanced and traditional materials may be significant and may have implications for life-cycle costs and potential liabilities. Respondents are not, however, greatly concerned about environmental consequences. About $54 \%$ of respondents suggest that the impacts of advanced materials use on the environment are only a minor problem; $29 \%$ believe the impacts are not a problem; and $17 \%$ suggest the impacts are a major problem.

\subsubsection{Advanced Materials Exhibit Different Life-Cycle Cost than do Traditional Materials}

Our conceptual section suggests that advanced materials often cost more than traditional materials at purchase, but provide benefits over the life of the material that exceed those of traditional materials. This basic difference suggests that economic viability must be assessed in terms of life-cycle costs. Comparisons of advanced and traditional materials on the basis of, for example, cost per pound can result in misleading conclusions.

About $66 \%$ of respondents believe that the higher costs of advanced materials are a major problem. Another $29 \%$ believe higher costs to be a minor problem. Respondents are, however, split on whether advanced materials exhibit higher life-cycle costs. Some $52 \%$ of respondents agree or strongly agree with the statement that advanced materials exhibit greater life-cycle costs than do traditional materials, while $48 \%$ disagree or strongly disagree with the statement. Respondents do generally agree that the costs of advanced materials are more uncertain. About $68 \%$ of respondents agree or strongly agree with the statement that future supplies and costs are more uncertain for advanced materials than for traditional materials. This response suggests that adopters of advanced materials will use a higher discount rate in evaluating the benefits of advanced materials as compared 
to the discount rate used for traditional materials. In other words, advanced materials will be adopted only if the difference between the life-cycle costs of advanced and competing traditional materials is great enough to overcome the greater uncertainties associated with the use of advanced materials.

\subsection{The Structure of the Market for Advanced Materials Differs from that for Traditional Materials}

Our conceptual section suggests numerous reasons why the structure of advanced matcrial markets may differ from the structure of traditional material markets. As a result, we have suggested that BOM examine the determinants of the structure of advanced material markets and provide information on those determinanis.

Respondents generally agree with our assertion that the market structures do differ. About $85 \%$ of respondents agree or strongly agree with the statement that the structure of the advanced materials industry differs significantly from the structure of the conventional materials industry.

\subsection{The U.S. May Be at a Disadvantage in Competing with Foreign Competitors in the Advanced Materials Market}

In the course of discussing conceptual differences between advanced and traditional materials, it was suggested that the United States may have difficulty in competing with foreign competitors in the advanced materials market. The reasons include different organizational structures, different capabilities to provide required inputs at lowest cost, and different capabilities to move R\&D from the public sector to the private sector.

Respondents generally agree that the U.S. is currently at a disadvantage. When asked to rate the severity of problems resulting from the ability of the U.S. advanced materials industry to compete with foreign competitors, some $46 \%$ of respondents rated the problems as major. Another $34 \%$ rated the problems as minor. About $56 \%$ of respondents rated the problems resulting from the United States' competitive disadvantage in commercializing advanced materials as being major. Another $30 \%$ rated those problems as being minor. These results suggest that BOM should identify the problems 
that may limit the United States' competitiveness in the advanced materials market and provide relevant information on relevant parameters. Unfortunately, the relevant parameters will likely differ from advanced material to advanced material. Analyses will be required on a material-by-material basis to assess the most important determinants of international competitiveness. 


\section{CONCLUSIONS}

\subsection{OVERVIEW}

This report presents the findings of a study to assess needs for information about advanced materials. BOM currently provides information on traditional materials in several publications, such as its Minerals Yearbook and Mineral Facts and Problerns (which have recently been combined into one publication). The information format of this publication is suggested as a starting point for a similar publication on advanced materials.

There are significant differences, however, between traditional and advanced materials. The approach in this study was to review the literature comparing these two broad categories of materials. This review helped in identifying twelve general, fundamental differences. These differences in turn suggested the types of information that would be most useful, compared with the types of information normally provided on traditional materials. The differences also suggest the need to analyze special issues that arise from the unique nature of advanced materials.

In addition to this conceptual study, an empirical analysis was completed. The results were based on a questionnaire sent to about 1000 people who were thought to have interest in information on advanced materials. There were almost 200 respondents. Their responses generally confirmed the propositions set forth in the conceptual part of the study. They also provided data on the types of information that are of greatest interest to potential users.

The diversity of advanced materiais suggests strongly that to take a broad-brushed approach and to discuss advanced materials in aggregate or very general terms would be a great oversimplification, misleading, and hardly useful. For BOM, diversity presents a great challenge. It suggests the need for a concerted and coordinated effort to compile information on individual advanced materials rather than simply on broad categories of materials. Even with a concerted effort, the Materials Branch, which has primary responsibility for compiling the information, has limited staff 
resources. Thus, a coordinated effort will be needed. The Branch can benefit from assistance of other staff of the Division of Mineral Commodities. In studying information on the traditional minerals, the Division's staff would also assimilate information on advanced materials (e.g., silicon and silicon nitride). The staff of the Division of International Minerals can be helpful in identifying data sources for each country. As advanced materials continue to grow in importance, staff in other Divisions will undoubtedly' encounter information of direct or indirect relevance to advanced materials.

\subsection{MATERIALS OF GREATEST INTEREST}

Even with a concerted, coordinated effort, it will still be impossible to compile a comprehensive information base on all advanced materials in one year, or even in a few years. The number is too great. Thus, the Bureau should concentrate first on the materials of greatest interest to users and that will have the greatest impact on the national economy. Further study will be required on the latter, but the survey sheds light on the materials of greatest interest:

- composite engineering polymers,

- structural metals,

- structural ceramics,

- structural engineering polymers,

- composite metals, and

- electronic and optical functional devices (these being of great interest to a narrower audience).

Many respondents to the questionnaire are expected to use information on these materials on a daily basis. 
Both the conceptual and empirical analyses indicate that, compared to information on traditional materials, greater emphasis should be given to the attributes that distinguish advanced materials from traditional materials. Respondents to the questionnaire had the greatest interest in the properties of the materials, their uses, technology, prices, and the costs of production. This interest reflects the economic competitiveness - both at the firm and at the international levels - that may be driving the development of advanced materials and of which advanced materials have become a symbol. Information on fabrication, recycling and environmental issues, and life-cycle costs are of particular importance with advanced materials.

Thus, a general outline for a chapter on information on an advanced material might look like this:

I. Description of the material: key properties, sources of detailed data on properties, sources of information on recent scientific developments, and a description of end-uses.

II. World-wide market information on a regional basis: important countries, industry structure, and summary production, consumption, and trade data.

III. Technology: current technology and trends, technical and economic information on fabrication, life cycle costs, and sources of R\&D information.

IV. Operating issues: recycling and environmental impacts, legislative and government programs, and sources of information on technology transfer and other assistance programs.

\subsection{ANALYSIS AND OTHER ISSUES}

Our conceptual study pointed out a number of problem areas. These concerns were substantiated in the survey. Problems include: the lack of standards, performance reliability, fabrication techniques, higher costs to produce advanced materials relative to traditional materials, and the competitive disadvantage of the U.S. in commercializing advanced-material products. These areas are, for the most part, barriers to the application and use of advanced materials. 
As more data and other information are collected, BOM can help domestic industries and policy makers by analyzing important issues. Some of these include

- forecasting the demand, substitution, and market penetration of advanced materials - either specific materials, or generic ones defined on the basis of important properties;

- assessing organizational structures and their impacts on research, development and production;

- estimating life cycle costs and benefits of advanced materials; and

- examining the potential for recycling and the environmental consequences of producing and using advanced materials.

Identifying information and analysis needs for advanced materials requires a fundamental rethinking of why information of various types is important and to whom and for what purposes that information may be useful. With a rethinking of these information needs and providing quality information and analysis, the Bureau can play a role in helping the competitive position of domestic industries and informed decision making by policy makern. 


\section{APPENDIX A}

(The number in parenthesis beside each question indicates the number of respondents for a particular question or response.) 


\title{
ADVANCED MATERIALS: INFORMATION NEEDS, SOURCES AND ANALYSIS
}

\author{
Developed by \\ ENERGY AND ECONOMIC ANALYSIS SECTION \\ ENERGY DIVISION
}

\begin{abstract}
OAK RIDGE NATIONAL LABORATORY
Operated by

MARTIN MARIETTA ENERGY SYSTEMS, INC.

for the

U.S. DEPARTMENT OF ENERGY

under contract no. DE-AC05-84OR21400
\end{abstract}


1. Listed below are some posslble components of a definition for advanced materials. For each, please indicale whether that component is essential to the definition of advanced materials, Important, unimportant, or should not be included In the delinition which would disingulsh advance materials from traditional materlals. Please elrcie the numiter correspondling 10 the best answer.

\begin{tabular}{|c|c|c|c|c|c|}
\hline A. & Orealer strength & $\begin{array}{l}\text { ESSENTTAL } \\
\qquad|55|\end{array}$ & $\begin{array}{c}\text { IMPORTANT } \\
2[88]\end{array}$ & $\begin{array}{c}\text { UNIMPORTANT } \\
3[12]\end{array}$ & $\begin{array}{c}\text { SHOULDNT INCLUDE } \\
+|7|\end{array}$ \\
\hline B. & $\begin{array}{l}\text { Higher strenglh/ } \\
\text { densily ratlos }\end{array}$ & $1 \mid 81]$ & $2[74\}$ & $3[6]$ & $+|2|$ \\
\hline $\mathrm{C}$. & Creater hardness & $1[16]$ & $2[86]$ & $3[47\rceil$ & $4(0)$ \\
\hline D. & $\begin{array}{l}\text { Superior thermal } \\
\text { propertles }\end{array}$ & $1[55]$ & $2[92]$ & $3[8]$ & $4|4|$ \\
\hline$E$ & $\begin{array}{l}\text { Superior electrical } \\
\text { properties }\end{array}$ & $1[41]$ & $2[86]$ & $3[25]$ & $4[8]$ \\
\hline F. & $\begin{array}{l}\text { Superior optical } \\
\text { properties }\end{array}$ & $1[29]$ & $2\lfloor 75\rfloor$ & $3[41]$ & $4[13]$ \\
\hline o. & $\begin{array}{l}\text { Superior chemical } \\
\text { properties }\end{array}$ & $1[30]$ & $2[95]$ & $3[22]$ & $4(7)$ \\
\hline
\end{tabular}

2. Please list any additional material properties that should be included in the definition.

3. From the following list of advanced materials categories, please indicate whether each is very important, somewhat important, or unimportant to you in your present work.

$\begin{array}{ccc}\begin{array}{c}\text { VERY } \\ \text { IMPORTANT }\end{array} & \begin{array}{c}\text { SOMEWHAT } \\ \text { DMPORTANT }\end{array} & \begin{array}{c}\text { NOT } \\ \text { IMPORTANT }\end{array} \\ 1[70] & 2[41] & 3[59] \\ 1[7] & 2[34] & 3[129] \\ 1[69] & 2[58] & 3[45]\end{array}$

Carbide/Nitride Reinforcements in Metal Matrix) 


$\begin{array}{ccc}\begin{array}{c}\text { VERY } \\ \text { IMPORTANT }\end{array} & \begin{array}{c}\text { SOMEWHAT } \\ \text { IMPORTANT }\end{array} & \begin{array}{c}\text { NOT } \\ \text { IMPORTANT }\end{array} \\ 1[57] & 2[69] & 3[50] \\ 1[77] & 2[54] & 3[45]\end{array}$

E. Composile Structural Coramias (Sillcon Carblde/Nitride Reinforcements in Oxides and Non-Oxides)

F. Structural Engincering Polymers

$1[65$

2 [59]

$3[50]$

G. Composite Engincering Polymers (Flber Reinforcements in

1[91] $2[37] \quad 3[46]$

Thermoplastic and Thermosel Resins)

H. Electronic and Oplical Functional Devices (Dielectrics, Ferroelectrics and Superconductors)

1. Magnetic Functional Devices (Powder Alloys and Ferriles)

$1[6 !] \quad 2[49] \quad 3[66]$

J. Structural Medical and Dental (Hydroxyapatite, Carbon Fibers)

K. Functional Medical and Dental (Fluoropolymers, Acrylic Resins)

$1[25] \quad 2[60] \quad 3[86]$

L. Other

$1[15] \quad 2[43] \quad 3[113]$

$1[11] \quad 2[45]$

$1[29]$

4. Please Circle the letter of the above category that is the most important to you in your work.

\begin{tabular}{cccccccccccc}
{$[33]$} & {$[1]$} & {$[12]$} & {$[16]$} & {$[17]$} & {$[15]$} & {$[36]$} & {$[18]$} & {$[2]$} & {$[1]$} & {$[0]$} & {$[0]$} \\
$\mathrm{A}$ & $\mathrm{B}$ & $\mathrm{C}$ & $\mathrm{D}$ & $\mathrm{E}$ & $\mathrm{F}$ & $\mathrm{G}$ & $\mathrm{H}$ & $\mathrm{J}$ & $\mathrm{J}$ & $\mathrm{L}$ \\
\hline
\end{tabular}


5. The following 11 groups of advanced materials correspond to the categorizatlon scheme used earller, Here, however,

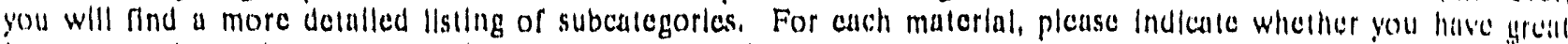
interest, moderate interest, or no interest for your work.

$\begin{array}{lcc}\text { OREAT } & \text { MODERATE } & \text { NO } \\ \text { INTEREST } & \text { INTTREST } & \text { INTEREST }\end{array}$

A. Structural Metals

1) Superalloys

2) Aluminum-Lithlum Alloys

$1[52]$

1 (42)

3) Amorphous Alloys

4) Rapldly Solldilled Alloys

1 (22)

1 [37]

1 [37]

5) Superfine Particles

6) Ordered Intermetallias

1 [39]

7) Shape Memory Alloys

1 [18]

8) Copper-Beryllium Alloys

1 [19]

9) Surface Hardened and

1 [44]

Coated Metals

10) Titanlum Alloys

11) Other (specify]

$1[50]$

$1[11]$

$2[54]$
$2[51]$
$2[60)]$
$2[59]$
$2[55]$
$2[49]$
$2[50]$
$2[41]$
$2[59]$
$2[51]$
$2[5]$

$3[56]$

$3(70)$

3 [80]

$3[66]$

3 [73]

3 [75]

$3[96]$

31100

3 [64]

3 [63]

$3[31]$

B. Absorptive Metals

1) Hydrogen Storage Alloys

$1[7]$

1 [5]

1 [2]

2 [26]

2 [34]

3 [132]

2) Porosity Metals

3) Other (specify)

$2[6]$

3 [128]

3 [81]

C. Metal Comparites

1) Whiskers

2) Particulates

3) Oxides or Carbide

Reinforcements in Metal Matrices

4) Other (specify)

D. Monolithic Structural Ceramics

1) Oxides

2) Non-oxides

3) Other (specify)

E. Comparite Structural Ceramics

1) Reinforcements in Matrices

2) Carbon Matrix/Carbon

3) Other (specify)

1 [ด]

2 [5]

3 [37] 


$\begin{array}{ccc}\text { OREAT } & \text { MODERATE } & \text { NO } \\ \text { INTEREST } & \text { INTEREST } & \text { INTEREST }\end{array}$

F. Structural Englneering Potymers
1) Thermoplastios
3) Polyurethane Foam
d) Liquild Crystal Polymers
5) Polymer Blends
6) Othor (speclfy')

$1[72]$

$1[60]$

$2[44]$

$2[51]$

$1[14]$

1 [36]

1 [44]

$1[7]$

$2[45]$

2 [50]

2 [47]

$2[7]$

$3[50]$

$3[55]$

3 [101]

3 [78]

3 (71)

$3[41]$

O. Comparite Enfineering Pobsmers
1) Fiber/Whiskor
Reinforcements in Thermosets
2) Fiber/Whisker
Reinforcoments in Thermoplasiles
3) Other (specify)

$1 \mid 67]$

$2[46]$

3 [53]

1 [67]

2 [50]

3 [49]

1 [9]

3 [38]

H. Electronic and Optical Functional Devices
1) Dielectrics
2) Ferroclectrics
3) Plezoelectries
4) Semiconductors
5) Lighil Emilters
6) Opilcal Fibers
7) Ionic Conductors
8) Superconductors
9) Other (specify)

1. Magnetic Functional Devices
1) Metallic
$1[29]$
2) Ceramic
3) Olher (specify)

J. Structural Mediral and Dental
1) Alumina Structures
2.) Hydroxyapatile
3) Carbon Fiber/Polylactic Acld Composiles
4) Other (specify)

K. Functional Medical and Dental
1) Sillcone
2) Fluoropolymers
3) Acrylias
4) Other (specify) 


\section{OREAT}

IN'TEREST

$1[20]$
MODERATE

INTEREST

2
No

INTTEREST

3

6. Tho following statements suggest differences between tradlional and advanced materlals. Please clrcle the number that besi describes whether you dlsagree, or agree that the statement is useful in distinguishing advanced materlals from tradilional malerials.

\section{STRONOLY \\ DISACREE}

materials penetrate their potentlal markets is fastor than for tradilional materlals.

B. Propertles of advanced materials can be customizal more easily than can propertles of tradilional materials.

C. The structure of the advanced materials indusiry (Iirm size, degree of vertical inlegration, etc. differs significanily from the structure of the conventional materials indusiry.

D. Advanced malerlals are less dependeni on supplies of strategic malerials and more dependent on processing lechnologies than are tradilional materlals.

E. Advanced malerials are more capable of serving small specialty markets than are iradilional malerials.
$130)]$

\section{DISAOREE AOREE}

2 [101]

$3[44]$

$4[4]$

$1[10]$

2 [54]

3 [86]

4 [27]

$1[3$

2 [23]

3 [109]

4 [42]

$1[5]$

$2[47]$

3 [72]

$4[53]$

1 [5]

2 [31]

$3[100]$

$4[42]$ 
STRONOLY

DISAOREE

I [11]

DISAGREE

181

$2[50]$

$3[99\}$

$4|22|$

are more uncerlain for advanced malerlals than for tradlional matcrials.

H. The potential for recycling advanced materals is more limlied than that for tradiluonal materials.

1. Advanced materials are lerss vulnerable to disruptions of raw materials than are traditional matorials.

J. Advanced materlals are more vulnerable 10 intermedlate products and processing technologies Imported from other countries than are tradillonal materials.

K. Development of advanced materials requires a much wider range of expertlse and scientinc knowledge than do traditonal materials.

L. Advanced materials requlre beller coordinated technology transfer between the public and privale sectors than do Iradillonal materials.

M. Other 171
$17]$

$2[49]$

3 [97]

$4|24|$

1 [9]

$2[88]$

$3[63]$

$4(13)$

1 [8]

2 [86]

$3[6]$

$4[12]$

1 [1]

$2[16]$

3 [85]

4 [79]

14]

$2[28]$

3 [78]

$4[72]$
1
3

4 
7. The increased use of advanced materials raises importan! issues and potential problems. Please circle the number that best describes your assessment of the aegree to which each issue listed below is a problem with the use of advinciud materials.

\section{NOT \\ A PROBLEM \\ A MINOR \\ P'ROBLEM \\ A MAJOR \\ PROBLEM}

$1[72]$

$2[87]$

raw materials used in

the manufacture of

advanced materials.

B. Limited availability of advanced materials

$1[34]$

$2[85]$

$3[62]$

$1[70]$

$2[82]$

$3[29]$

miaterials on markets for

traditional materials

D. The impact on advanced materials production due to their by-product relationships to traditional inaterials production

E. The limited recyclability of advanced materials

F. The impacts of advanced materials use on the environment

G. Limited advanced materials research needs

$1[67]$

$2[84]$

$3[15]$
$3 \cdot[22]$
$1[43] \quad 2[94]$

$1[52] \quad 2[56] \quad 3[30]$

$1[35] \quad 2[60] \quad 3[60]$

$1[13] \quad 2[56 \quad 3[113]$

for advanced materials

$1[20]$

$2[61]$

$3[98]$

of advanced materials

$1[7]$

2 [42]

3 [130]

fabrication techniques

$\mathrm{K}$. Higher costs of advanced materials

$1[9]$

$2[52]$

$3[120]$ 


\section{NOT \\ A PROBLEM}

L. The ability of the U.S. advanced materials industry to conipete with forcign competitors

M. The vulnerability of U.S. producers of advanced materials to foreign control of raw materials and/or technology

N. The vulnerability of U.S. consumers of advanced materials to foreign suppliers

O. U.S. competitive disadvantage in commercializing advanced materials

P. Other [14]

Q. Other

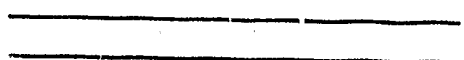

R. Other

$\longrightarrow$

1 [35]

A MINOR

PROBLEM

2 [61]

A MAJOR

PROBLEM

3 [81]

1 [37]

2 [88]

3 [53]

1 [38]

$2[86]$

3 [52]

$1[25]$

2 [53]

3 [99]

1

2

3

1

2

3

1

2

3

8. In Question 4 you selected the advanced materials category that is most important to you. Please refer to Question 4 and write the name of the category you selected as being most important in the following blank.

Advanced Material Category Most

Important to You 
Please circle the number that best describes your interest in obtaining the types of information listed below for the advanced material category you chose.

\section{GREAT INTEREST}

A. Industry structure (e.g., size, distribution, specifications)

B. Uses of the material

C. Raw materials for advanced materials

D. Current technology

E. Technology outlook

F. Supply/demand relationships (including imports, exports, stocks)

G. Demand forecasts

H. Supply forecasts

1. Byproducts and coproducts

J. Strategic considerations

$K$ Economic factors and problems (e.g., prices, costs of production)

L. Operating factors and problems (e.g., toxicity, environmental considerations, energy requirements)

M. Legislation and government programs

N. Properties of the material
1 [9]

$1[92]$ MODERATE INTEREST

2 [69]

$2[42]$

$3[5]$

1 [68]

2 [95]

3 [18]

1 [130]

2 [48]

3 [5]

1 [130]

$1[7]$

2 [49]

3 [5]

2. [78]

3 [26]

1 [70]

1 [27]

2 [64]

3 [20]

2 [89]

3 [21]

2 [104]

3 [48]

1 [83]

2 [71]

3 [25]

1 [119]

2 [53]

3 [11]

1 [95]

2 [72]

3 [16]

1 [78]

2 [84]

3 [20]

$1[136]$

2 [39]

3 [9] 
9. How do you use the types of information listed in Question 8? Please circle the number that best reflects your usc.

\section{WOULD NOT USE MIGHT USE WOULD USE}
A. Supply/demand/price
$1[30]$
$2[63]$
$3[84]$ projections
[58]
$2[48]$
$3[67]$
C. Policy analysis
1 [41]
2 [73]
3 [63]
D. Production decisions
$1[54]$
2 [69]
3 [49]
E. Consumption decisions
$1[54]$
2 [64]
3 [55]
F. Technical research and development
1 [28]
2 [31]
$3[117]$
G. Oiner $[9]$
1
2
3

10. Please circle the number that indicates how frequently you would use information on advanced materials.

1. ONCE A DAY [56]

2. ONCE A WEEK [44]

3. ONCE A MONTH [44]
4. ONCE EVERY SIX MONTHS [14]

5. ONCE A YEAR [5]

6. DONT KNOW [14]

11. Please circle the number that corresponds to the minimum level of information on advanced materials sufficient for your needs.
1. RAW DATA [37]
2. SUMMARY STATISTICS [74]
3. PROJECTIONS [44]
4. POLICY ANALYSIS [17]

12. Please circle the number that best describes your current employment.

1. PRODUCER OF ADVANCED MATERLALS [42]

2. CONSUMER OF ADVANCED MATERIALS [8]

3. SUPPLIER OF RAW MATERLALS FOR ADVANCED MATERIALS PRODUCTION [9]

4. SUPPLIER OF EQUIPMENT FOR ADVANCED MATERLALS PRODUCTION OR USE [2]

5. JOURNALIST [1]

6. EMPLOYEE OF FEDERAL AGENCY [38]

7. EMPLOYEE OF STATE AGENCY [2]

8. EMPLOYEE OF PRIVATE RESEARCH AND DEVELOPMENT ORGANIZATION [21]

9. EMPLOYEE OF PUBLIC RESEARCH AND DEVELOPMENT ORGANIZATION [22]

10. PUBLICLY ELECTED OFFICIAL [0]

11. EMPLOYEE OF SALES/MARKETING FIRM [3]

12. OTHER [31] 
13. Please circle the number that best describes your current job classification.

1. GEOLOGIST [2]

2. MINING ENGINEER [3]

3. MANUFACTURING/PROCESS ENGINEER [9]

4. ENGINEER (OTHER) [10]

5. ECONOMIST [14]

6. SOCIAL SCIENTIST [0]

7. ACCOUNTANT/FINANCIAL ANALYST [1]

8. LAWYER [0]
9. MATERLALS SCIENTIST [31]

10. CHEMIST [12]

11. POLICY ANALYST [7]

12. CORPORATE MANAGER [48]

13. MANAGER IN FEDERAL [18] OR STATE AGENCY

14. TECHNICIAN [0]

15. OTHER (specily)

14. If you or any other member of your organization is willing to respond to queries about advanced materials, such as data avallabllity, data sources, data needs, and so forth, please provide the following Information:

Contact Person

Area Code and Phone \#

Name of Organization

15. Also please circle the number or numbers that best describe(s) the information category or categories with which this contact person is most familiar.

1. INDUSTRY STRUCTURE (EG., SIZE, DISTRIBUTION, SPECIFICATION) [27]

2. USES OF THE MATERIAL [29]

3. RESERVES/RESOURCES OF ADVANCED MATERIAL INPUTS [4]

4. CURRENT TECHNOLOGY [6]

5. TECHNOLOGY OUTLOOK [2]

6. SUPPLYDEMAND RELATIONSHIPS (INCLUDE IMPORTS, EXPORTS, STOCKS) [6]

7. DEMAND FORECASTS [1]

8. SUPPLY FORECASTS [1]

9. BYPRODUCTS AND COPRODUCTS [0]

10. STRATEGIC CONSIDERATIONS [2]

11. ECONOMIC FACTORS AND PROBLEMS (E.G., PRICES, COSTS OF PRODUCTION) [0]

12. OPERATING FACTORS AND PROBLEMS (E.G.,TOXICITY, ENVIRONMENTAL.CONSIDERATIONS, ENERGY REQUIREMENTS) [0]

13. LEGISLATION AND GOVERNMENT PROGRAMS [2]

14. PROPERTIES OF THE MATERLAL [3] 
Thank you very much for your assistance. If you have any additional comments you would like to add on informallon neuds for advanced materials, please use the space below. If you would like to be informed about information on advanced materials as it becomes avallable, please write your name and address below.

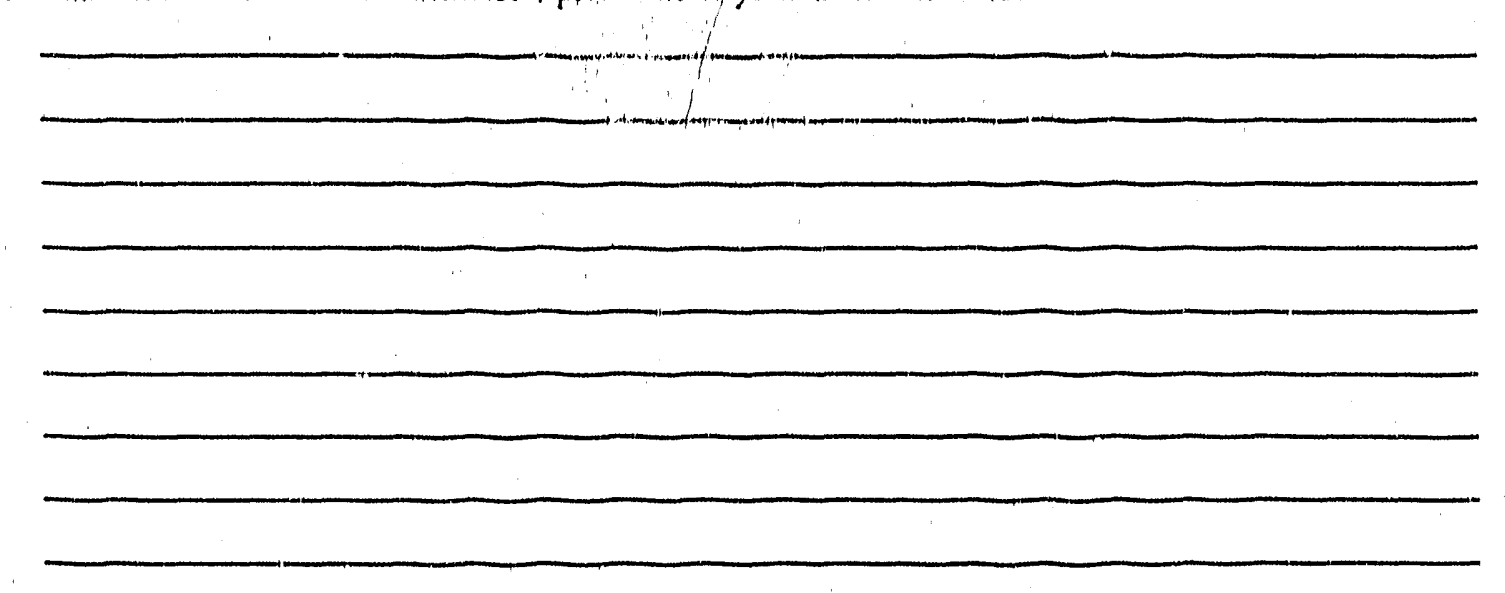

Please retum the questionnaire in the anclased self-addressed stamped envelope. Thank you very much for your help. 


\section{BIBLIOGRAPHY}

Balazik, R. F. and B. W. Klein 1987. "The Impact of Advanced Materials on Conventional Nonfucl Mineral Markets: Selected Forecasts for 1990-2000," IC-9150, U.S. Bureau of Mines, U.S. Department of the Interior, Washington, D.C.,

Balazik, R. F, 1988. "The Significance of Modern Materials: Impact and Policy Implications," Minerals and Materials: A Bimonthly Survey, December 1987-January 1988, pp. 25-30 in U.S. Bureau of Mines, U.S. Department of the Interior, Washington, D.C.

Clark, J. P. 1989. "Markets and Information Requirements for Advanced Materials," presented at the Conference on Advanced Materials: Outlook and Information Requirements; U.S. Bureau of Mines, Alexandria, Va., Nov. 7.

Clark, J. P. and M. C. Flemings 1986. "Advanced Materials and the Economy," Scientific American 255(4): 51-57, Ostober.

Compressed Air Magazine 1985. "Imagination Soars with Advanced Materials," September, pp. 10-17.

Curlee, T. R. 1988. "Innovations in Materials and Materials Processing: The Potential for Energy Conservation," Materials and Society 12(1): 1-45.

Fraser, S., A. Barsotti, and D. Rogich 1988. "Surting Out Materials Issues," Resources Policy 14(1): 3-20, March.

Fraser, S., D. Rogich, and A Barsotti 1987. "Competition Among Materials: Implication for the Domestic Mineral Industry," Minerals and Materials, April/May, pp. 7-14.

Frey, D. N. 1988. "The Process of Processing: How to Commercialize It All," in Advanced Materials in the Manufacturing Revolution, ANL-89/3, CONF-88-6303, Argonne National Laboratory, Argonne, Ill.

Fuqua, D. 1986. "The Importance of Advanced Materials to Our National Science Perspectives," Advanced Ceramic Materials 1(3): 219-22.

Ginley, D., R. Hurdelbrink, and J. F. Lemons, Jr. 1989. "I.tsarnational Competition in Transportation and Construction," Materials and Society 13(3): 211-32.

Haeberle, R. M. 1987. "Development of Mechanically Alloyed Products for Advanced Materials Applications," Materials and Society 11(2): 179-88.

Hausman, J. A. 1979. "Individual Discount Rates and the Purchase and Utilization of Energy-Using Durables," Bell Journal of Economics 10(1): 50-54, Spring. 
Hondros, E. D. 1986. "Materials, Year 2000 -. A Perspective," International Joumal of Materials and Product Technology 1(1): 1-22.

Kraemer, S., D. Ginley, and C. Joyce. 1989. "The Life Cycle Analysis of Materials Competition for Pipe in the Construction Industry," presented at the Conference on Polymer Materials Systems Analysis, Technology Transfer Seminar, Nov, 6, Alexandria, Md.

Kupczyk, S. 1988. "Supportability of Composite Airframes: Civilian and Military Aspects," Composite Structures 10: 37-50.

Landsberg, H. H. and M. K. Macauley 1988a. Economics of Advanced Materials, Resources for the Future, Energy and Materials Division, Washington, D.C., April.

Landsberg, H. H. and M. K. Macauley 1988b. Encounter with the Advanced Materials, Resources for the Future, Energy and Materials Division, Washington, D.C., February.

Malpas, R. 1987. "Genesis of Advanced Materials-Based Market Products: Technico-Economic Aspects," Philosophical Transactions of the Royal Society of London, Ser. A. 322: 347-60.

Marcum, J. M. 1987. "Policies Plans, and Research and Development Investment in Advanced Materials in the Major Countries," Philosophical Transactions of the Royal Society of London, Ser. A. 322: 311-21.

Maxwell, P. C. 1985. "Materials Policy -- A Congressional Perspective," Materials and Society 9(2): 251-55.

McLaren, M. G. 1988. "The Opportunity in Advanced Ceramics and the Potential Markets," Materials and Society 12(3/4): 223-38.

Mining Joumal 1988. "The Advanced Materials Phenomenon," p. 246, March 25.

Mooney, P. J. 1989. "Plastics as Advanced Materials Competing with Metals," presented at the Conference on Advanced Materials: Outlook and Information Requirements, U.S. Bureau of Mines, Alexandria, Va., Nov. 7.

National Research Council 1989. "Data Needs for High-Tech Materials: A Report of a Meeting Held June 13, 1988," Numerical Data Advisory Board, National Academy Press, Washington, D.C.

Office of Technology Assessment 1988. Advanced Materials by Design, U.S. Congress, U.S. Government Printing Office, Washington, D.C., June.

Riggs, J. P. 1988. "Developing Trends and Characteristics of High Performance Polymers and Composites: Manufacture, Supply, and Use," in Advanced Materials in the Manufacturing Revolution, ANL-89/3, CONF-8806303, Argonne National Laboratory, Argonne, III. 
Schmitt, B. 1988, "Advanced Material Funding Said to Be "Schizophrenic"," American Metal Market, p. 4 , July 6.

Sorrell, C. A. 1987. "Bureau of Mines Activities in Advanced Materials," Minerals and Materials: A Bimonthly Survey; Octọber/November, pp. 11-20.

Sundaresan, S. 1988. "Selecting and Designing with Tomorrow's Advanced Materials," Advanced Materials and Processes, January, pp. 74-77.

Uchida, M. 1986. "Advanced Materials and Japanese Industry," Chemical Economy and Engineering Review 18(9): 12-24, September.

United States Bureau of Mines. 1987. "Bureau of Mines Activities in Advanced Materials: Definitions and Guidelines", Office of Advanced Materials Coordination, OFR 4887, December, pp. 1. 

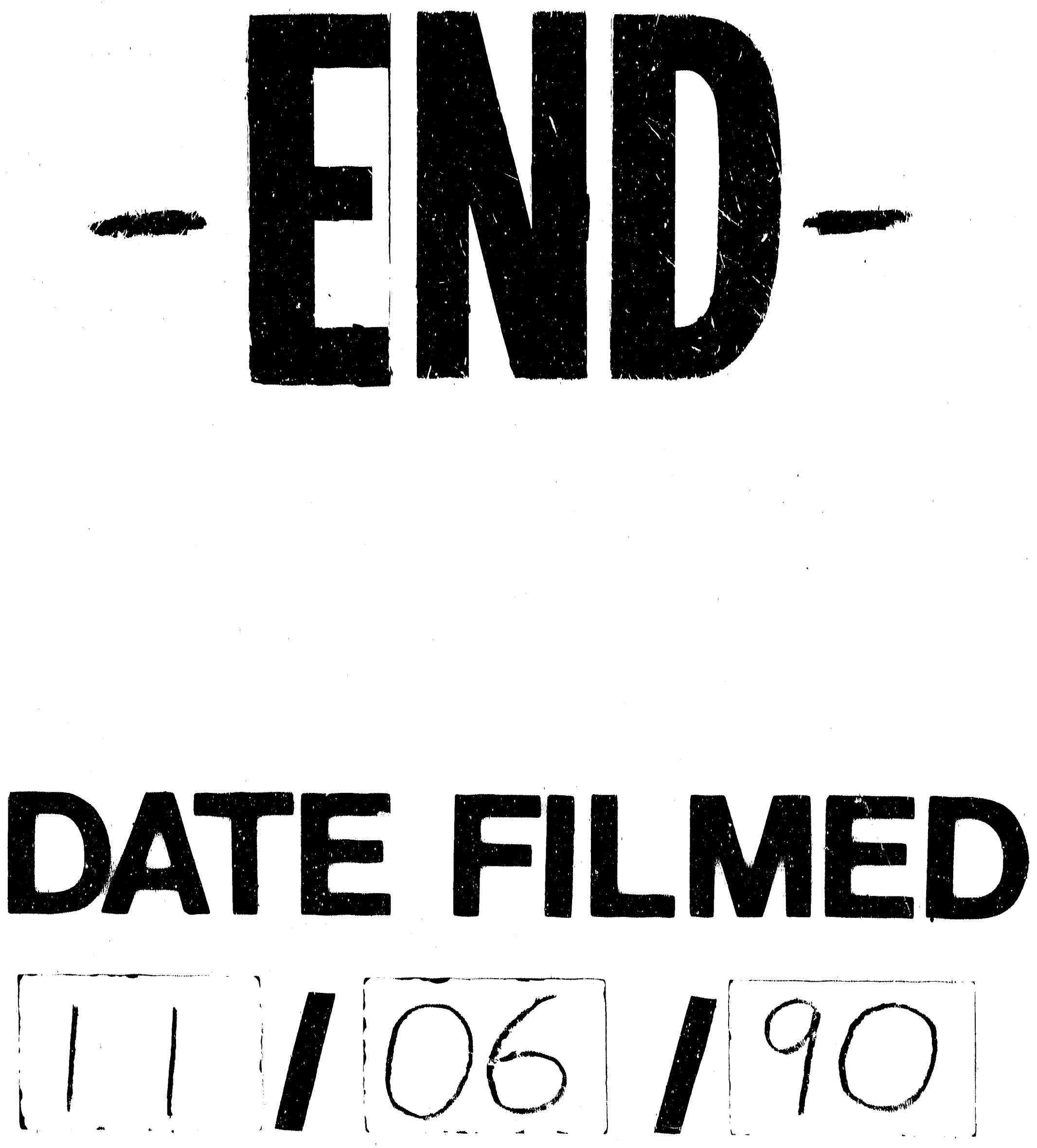
